\title{
Wnt canonical pathway activator TWS119 drives microglial anti-inflammatory activation and facilitates neurological recovery following experimental stroke
}

Degang Song ${ }^{1,2,3}$, Xiangjian Zhang ${ }^{1,2^{*}}$ (D) Junmin Chen ${ }^{1,2}$, Xiaoxia Liu ${ }^{1,2}$, Jing Xue ${ }^{1,2}$, Lan Zhang ${ }^{1,2}$ and Xifa Lan ${ }^{3}$

\begin{abstract}
Background: Ischemic stroke is a leading cause of disability worldwide and characteristically accompanied by downregulation of the $\mathrm{Wnt} / \beta$-catenin signaling. Activation of $\mathrm{Wnt} / \beta$-catenin signaling emerges to attenuate neuroinflammation after ischemic stroke; however, its effect on modulating microglial polarization is largely unknown. Here, we explored whether Wnt/ $\beta$-catenin pathway activator TWS119 facilitated long-term neurological recovery via modulating microglia polarization after experimental stroke.
\end{abstract}

Methods: Ischemic stroke mice model was induced by permanent distal middle cerebral artery occlusion plus $1 \mathrm{~h}$ hypoxia. TWS119 was administrated from day 1 to 14 after stroke. Neurological deficits were monitored up to 21 days after stroke. Angiogenesis, neural plasticity, microglial polarization, and microglia-associated inflammatory cytokines were detected in the peri-infarct cortex at days 14 and 21 after stroke. Primary microglia and mouse brain microvascular endothelial cell lines were employed to explore the underlying mechanism in vitro.

Results: TWS119 mitigated neurological deficits at days 14 and 21 after experimental stroke, paralleled by acceleration on angiogenesis and neural plasticity in the peri-infarct cortex. Mechanistically, cerebral ischemia induced production of microglia-associated proinflammatory cytokines and priming of activated microglia toward pro-inflammatory polarization, whereas TWS119 ameliorated microglia-mediated neuroinflammatory status following ischemic stroke and promoted angiogenesis by modulating microglia to anti-inflammatory phenotype. The beneficial efficacy of TWS119 in microglial polarization was largely reversed by selective Wnt/ $\beta$-catenin pathway blockade in vitro, suggesting that TWS119-enabled pro-inflammatory to anti-inflammatory phenotype switch of microglia was possibly mediated by Wnt/ $\beta$-catenin signaling.

Conclusions: Wnt/ $\beta$-catenin pathway activator TWS119 ameliorated neuroinflammatory microenvironment following chronic cerebral ischemia via modulating microglia towards anti-inflammatory phenotype, and facilitates neurological recovery in an anti-inflammatory phenotype polarization-dependent manner. Activation of Wnt/ $\beta$ catenin pathway following ischemic stroke might be a potential restorative strategy targeting microglia-mediated neuroinflammation.

Keywords: Cerebral ischemia, WNT/ß-catenin, TWS119, Microglial polarization, Neuroinflammation, Neurological recovery

\footnotetext{
* Correspondence: zhangxj0706@aliyun.com

'Department of Neurology, Second Hospital of Hebei Medical University, 215

Hepingxi Road, Shijiazhuang 050000, Hebei, China

${ }^{2}$ Hebei Key Laboratory of Vascular Homeostasis and Hebei Collaborative

Innovation Center for Cardio-cerebrovascular Disease, 215 Hepingxi Road,

Shijiazhuang 050000, Hebei, China

Full list of author information is available at the end of the article
}

(c) The Author(s). 2019 Open Access This article is distributed under the terms of the Creative Commons Attribution 4.0 International License (http://creativecommons.org/licenses/by/4.0/), which permits unrestricted use, distribution, and reproduction in any medium, provided you give appropriate credit to the original author(s) and the source, provide a link to the Creative Commons license, and indicate if changes were made. The Creative Commons Public Domain Dedication waiver (http://creativecommons.org/publicdomain/zero/1.0/) applies to the data made available in this article, unless otherwise stated. 


\section{Background}

Ischemic stroke is a leading cause of disability worldwide [1]. Hyperacute intravenous thrombolysis and endovascular intervention have been performed in clinical practice. Nevertheless, the low revascularization rates due to short time window and side effects frequently cause cerebral ischemic injury [2]. In response to cerebral ischemia, the brain initiates self-repair mechanisms and undergoes a post-stroke neurorestorative process. Angiogenesis and neural plasticity are major post-stroke neurorestorative elements. Newborn cerebral microvessels derived from angiogenesis have been clinically regarded as the III level collateral circulation for restoring blood supply to the ischemic brain [3]. Extensive rewiring of remaining neuronal connections during the neural plasticity process leads to post-stroke cortical map rearrangement and functional improvement [4]. Unfortunately, the neurorestorative potential of the adult brain is very limited; ischemic stroke patients often suffer long-term neurological deficits [5]. Seeking promising strategies on facilitating post-stroke angiogenesis and neural plasticity is paramount for long-term functional improvement.

Post-stroke angiogenesis and neural plasticity are accompanied by long-lasting neuroinflammation, which provides a promising therapeutic opportunity to improve neurological outcome [6]. Microglia, as the main resident immune cells, display a beneficial efficacy in ameliorating inflammatory microenvironment for neurovascular remolding via shifting polarization from pro-inflammatory phenotype to antiinflammatory phenotype $[7,8]$. Indeed, mounting evidences demonstrate that the microglia with anti-inflammatory phenotype plays a neurorestorative role during the recovery period of ischemic stroke through secreting antiinflammatory cytokines $[9,10]$. Anti-inflammatory polarized microglia is a novel therapeutic target for post-stroke neurological recovery $[7,8,11]$.

The Wnt canonical or Wnt/ $\beta$-catenin pathway is a key mechanism involved in the maintenance of neuronal homeostasis [12]. Deregulation of the $\mathrm{Wnt} / \beta$-catenin pathway contributes to the pathological progression following neurodegenerative diseases, and it is emerging that the $\mathrm{Wnt} / \beta$-catenin pathway is involved in neuroinflammation following cerebral ischemia [13]. Growing evidences suggest that activation of the Wnt/ $\beta$-catenin signaling pathway modulates microglial polarization in vitro $[14,15]$ Interestingly, activation of the $\mathrm{Wnt} / \beta$ catenin pathway inhibits the release of proinflammatory cytokines and promotes switch of microglial polarization from pro-inflammatory phenotype to anti-inflammatory phenotype in hemorrhagic stroke model [16]. However, the exhaustive effect of Wnt/ $\beta$-catenin pathway on microglial polarization following ischemic stroke is largely unknown. 4,6-disubstituted pyrrolopyrimidine
(TWS119), a specific inhibitor of glycogen synthase kinase (GSK)-3 $\beta$, increases the protein level of $\beta$-catenin and activate the Wnt signaling pathway in the ischemic brai $\mathrm{n}[17]$. Furthermore, the Wnt canonical pathway activator TWS119 exerts favorable effects on immuneinflammation modulation $[18,19]$ and blood-brain barrier protection [17]. We speculated that TWS119 might show activated microglia toward anti-inflammatory phenotype and further facilitated neurological recovery following ischemic stroke. In the current study, we sought to examine the efficacy of the Wnt canonical pathway activator TWS119 on modulating microglial polarization in a focal cerebral ischemia model and focused on whether TWS119 facilitated neurological recovery in an antiinflammatory phenotype polarization-dependent manner.

\section{Methods \\ Animals}

Adult male C57BL/6 mice (weight $23-25$ g, 8-10 weeks) of SPF grade were obtained from the Vital River Laboratory Animal Technology Co., Ltd (Beijing, China). Mice were housed in a home cage with controlled temperature $\left(22 \pm 3{ }^{\circ} \mathrm{C}\right)$ and humidity $(60 \% \pm 5 \%)$ under a 12-h light/ dark cycle and were allowed water and food ad libitum.

Ischemic stroke was induced in male mice (10 weeks old) by permanent distal middle cerebral artery (MCA) occlusion plus $1 \mathrm{~h}$ hypoxia [20]. The operation was performed in a sterile operating room. Anesthesia was induced with isoflurane (induction dosage 3\%; maintenance dosage $1.5 \%$ ) in air mixture. During anesthesia, artificial tear ointment was applied for eye protection and lubrication, and sucking was performed regularly to prevent airway obstruction. The right MCA was permanently coagulated distal to the lenticulostriate branches with lowheat bipolar electrocautery (Bovie Aaron Medical, USA). To increase lesion size and consequently behavioral deficits, mice were immediately placed in a hypoxia chamber containing $8 \%$ oxygen for $1 \mathrm{~h}$ after MCA occlusion. Rectal temperature of each mouse was maintained at $37 \pm 0.5^{\circ} \mathrm{C}$ during the molding process using a heating pad. Mice were excluded from the study with the following conditions: subarachnoid hemorrhage occurred during operation; a recanalization of the MCA after two attempts of electrocoagulation; regional cortical cerebral blood flow reduction less than $30 \%$ of the baseline level. Shamoperated mice were subjected to the same surgery and hypoxia, but not occlude MCA.

TWS119 (diluted in 1\% DMSO, Selleck, Houston, TX, USA) was administrated to mice by intraperitoneal injection once daily from days 1 to 14 after surgery according to a treatment strategy described previously [7]. Intraperitoneal injection followed the aseptic principle and recommended procedures to avoid complications, such as peritonitis. The dose $(10 \mathrm{mg} / \mathrm{kg})$ of TWS119 was 
selected based on our previous results in the supplementary material. Mice were divided into 3 groups following the principle of randomization (random number): Sham group: sham-operated mice; Vehicle group: mice were subjected to cerebral ischemic injury and vehicle (1\% DMSO) treatment; TWS119 group: mice were subjected to cerebral ischemic injury and TWS119 treatment. The experimental scheme is schematically shown in Fig. 1a. Brain tissue for protein, gene, and cytokine detection were harvested from the peri-infarct region as described previously [21]. Immunofluorescence images were collected from the region of interest (ROI) in the ipsilateral peri-infarct cortex. The peri-infarct region $(0.5-\mathrm{mm}$-wide cortical region around brain infarction) and ROI are schematically shown in Fig. 1b.

\section{Primary microglia}

Primary microglia cells were prepared from the cerebral cortex of neonatal C57BL/6 mice at P1-P2 as previously reported with some modifications [15]. Briefly, mixed glial cells were cultured glucose DMEM (Cat No.: 11965-084, Gibco) supplemented with 10\% fetal bovine serum (Cat No.: 16000-044, Gibco) and 1\% penicillinstreptomycin (Cat No.: 15070-063, Gibco) and incubated at $37^{\circ} \mathrm{C}$ in a humidified incubator containing $5 \% \mathrm{CO}_{2}$ and $95 \%$ air (normoxic conditions) for 10 days. Next, microglia cells were separated from the mixed glia cells by shaking the flasks at 200 r.p.m at $37^{\circ} \mathrm{C}$ for $2 \mathrm{~h}$ and collected by centrifugation. Finally, the microglia cells were plated into six-well plates $\left(1 \times 10^{6} /\right.$ well $)$ with fresh medium for $24 \mathrm{~h}$ before ready for further treatment. The primary microglia cells were determined by immunofluorescence using ionized calcium-binding adapter molecule 1 (Iba-1, 1:500, Wako). The eligible purity of the obtained microglia cells was more than $95 \%$.

For pro-inflammatory phenotype polarization, serumstarved microglia were stimulated with lipopolysaccharide (LPS, $100 \mathrm{ng} / \mathrm{ml}$, Sigma) plus interferon- $\gamma$ (IFN- $\gamma, 20$ $\mathrm{ng} / \mathrm{ml}$, Sigma) for $24 \mathrm{~h}$ in normoxic conditions [22].

TWS119 $(10 \mu \mathrm{M})$ and/or the reversible inhibitor of Wnt/ $\beta$-catenin signaling pathway (IWR-1, $10 \mu \mathrm{M}$, Calbiochem) were used for treatment in vitro and added to the microglia cultures immediately following the application of LPS plus IFN- $\gamma$. IWR-1, a tankyrase inhibitor targeting Axin, lead to a degradation of $\beta$-catenin. The microglia cells were divided into 5 groups: control: microglia cells without LPS plus IFN- $\gamma$ stimulation and any treatment; LPS+IFN- $\gamma$ : microglia cells stimulated

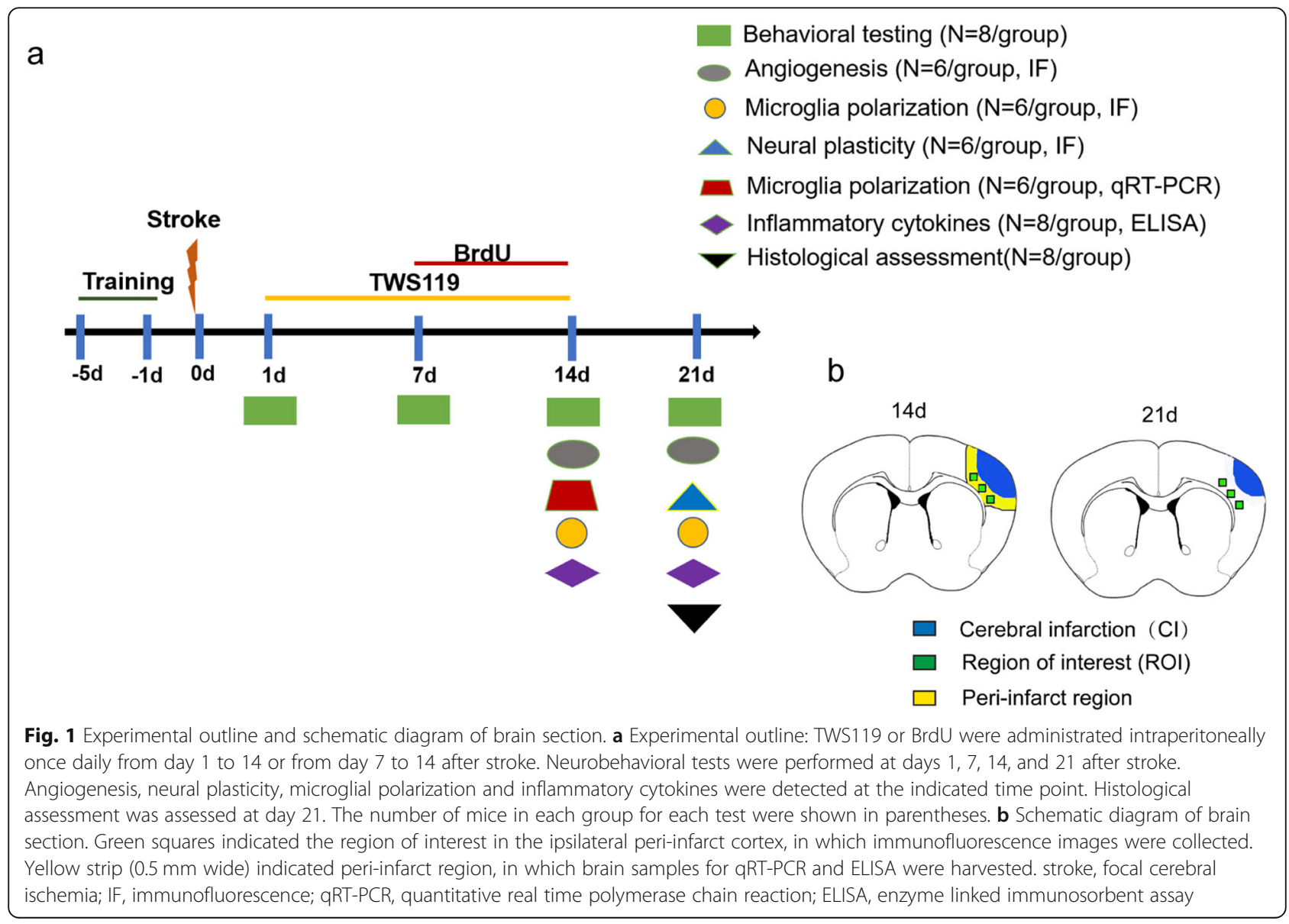


with LPS plus IFN- $\gamma$; LPS+IFN- $\gamma+$ TWS119: microglia cells stimulated with LPS plus IFN- $\gamma$ and treated with TWS119; LPS+IFN- $\gamma+$ IWR-1: microglia cells stimulated with LPS plus IFN- $\gamma$ and treated with IWR-1; LPS+IFN$\gamma+$ TWS119+IWR-1: microglia cells stimulated with LPS plus IFN- $\gamma$ and treated with TWS119 plus IWR-1. After $24 \mathrm{~h}$ of incubation, the $\beta$-catenin and pro-inflammatory/ anti-inflammatory phenotype marker of microglia cells were detected; microglia supernatants were collected and used as conditioned media $(\mathrm{CM})$; the inflammatory cytokines in microglia $\mathrm{CM}$ were evaluated.

\section{Mouse brain microvascular endothelial cell line}

The mouse brain microvascular endothelial cell line bEnd.3 (American Type Culture Collection (ATCC), Manassas, VA, USA) were used to evaluate angiogenesis in vitro.

Oxygen-glucose deprivation (OGD) injuries were used to mimic post-stroke ischemic damage as previously described [23]. In brief, bEnd.3 cells were cultured with glucose-free DMEM and incubated for $6 \mathrm{~h}$ in a humidified incubator containing $5 \% \mathrm{CO}_{2}$ and $95 \% \mathrm{~N}_{2}$ at $37^{\circ} \mathrm{C}$.

Pro-angiogenic structures of OGD bEnd.3 cells in DMEM and CM (microglia supernatant) were detected by tube formation assay [8]. Firstly, the bEnd.3 cells were divided into 3 groups and cultured in DMEM: bEnd.3: bEnd.3 cells without OGD injure and TWS119 treatment; OGDbEnd.3: bEnd.3 cells were subjected to OGD injure; OGDbEnd.3+TWS119: bEnd.3 cells were subjected to OGD injuries and TWS119 $(10 \mu \mathrm{M})$ treatment. Next, OGDbEnd.3 cells were divided into 6 groups: OGDbEnd.3: OGDbEnd.3 cultured in DMEM; control: OGDbEnd.3 cells were cultured in untreated CM; TWS119: TWS119 $(10 \mu \mathrm{M})$ were directly added in control; LPS+IFN- $\gamma$ : OGDbEnd.3 cells were cultured with LPS plus IFN- $\gamma$ stimulated CM; LPS+IFN $-\gamma+$ TWS119: OGDbEnd.3 cells were cultured with LPS plus IFN- $\gamma$ stimulated and FTY720 treated CM; LPS+IFN$\gamma+$ TWS119+IWR-1: OGDbEnd.3 cells were cultured with LPS plus IFN- $\gamma$ stimulated and TWS119 plus IWR1 treated CM.

\section{Neurobehavioral test}

CatWalk test, Adhesive Removal test, Accelerated Rotarod test, and modified neurological severity scores (mNSS) were used for assessing neurological deficits. CatWalk test, Adhesive Removal test, and Accelerated Rotarod test were performed three times for each mouse and needed 5 days of training for adaptability.

CatWalkXT (v10.6, Noldus Information Technology) test was used to measure Walking performance of ischemic mice as described previously [24]. Each mouse walked freely through a corridor on a glass walkway illuminated with beams of light from below. Walking at a steady speed (no stopping, rearing, or grooming) was defined as a successful walking trial, which was performed 3 times for each mouse. The footprints were collected using a camera and then analyzed using CatWalkXT software. Swing speed $(\mathrm{cm} / \mathrm{s})$, stride length $(\mathrm{cm})$, and paw intensity (arbitrary units, 0-255) of the left front limb (cerebral ischemia-affected limb) were selected for gait analysis.

Adhesion Removal test was selected to monitor sensorimotor function and postural asymmetry ischemic mice $[25,26]$. Briefly, two adhesive tapes $\left(0.3 \times 0.4 \mathrm{~cm}^{2}\right)$ were attached to each paw of the mice with equal pressure; the order of placing adhesive (right or left) was distinct between each animal and each session. The mice were placed in a Perspex box; contact time (the point that the mouse reacts to the presence of adhesive strips) and Adhesive Removal time were collected, with a maximum of $120 \mathrm{~s}$.

Accelerated Rotarod (Ugo Basile 47600, Ugo-Basile, Biological Research Apparatus, Milan, Italy) test was performed to evaluate motor coordination and learning function of ischemic mice according to a previous study [27]. The mice were placed on a gradually accelerated rotating rod ( 4 to $10 \mathrm{rpm}, 5 \mathrm{~min}$ ). Resident time on the rotating rod (latency time) of each mouse was recorded.

Modified neurological severity scores (mNSS) were performed to evaluate functional impairments [28]. The scores were graded on a scale ranging from 0 to 18 (normal score 0, maximal deficit score 18); the higher the scores, the worse neurological function was. The scores for each mouse were recorded at days $1,7,14$, and 21 after ischemic injury.

\section{Histological assessment}

Cortical width index (CWI) was used to assess histological damage as described previously [7]. Whole brain images were captured using a digital camera and analyzed using the ImageJ software (NIH, USA). The injury contralateral width (W.contra) from the lateral edge to the midline and the injury ipsilateral width (W.ipsi) from the edge of cortical cavitation to the midline were measured. Measurements were performed at the midpoint of the forebrain. CWI $=$ W.ipsi $\times 100 \% /$ W.contra.

\section{Immunofluorescence staining}

Mice were deeply anesthetized and then fixed by transcardial perfusion with cold saline followed by $4 \%$ paraformaldehyde. Coronal slices $(15-\mu \mathrm{m}$ thick) were obtained from the brain blocks centered on the ischemic lesion (approximately bregma $-1.5 \mathrm{~mm}$ to $+0.5 \mathrm{~mm}$ ) using a cryostat microtome (LEICA CM1850, Leica Biosystems, Wetzlar, Germany). Three slices randomly selected from every 10th coronal slices were used for each immunohistochemical staining item. The brain slices were washed by PBS 3 times at 10-min intervals, then 
permeabilized by $0.3 \%$ Triton X-100. After $1 \mathrm{~h}$ blocking using $10 \%$ donkey serum albumin, the slices were incubated overnight at $4{ }^{\circ} \mathrm{C}$ with the following primary antibodies: Synaptophysin (1:200, Abcam); Postsynaptic dense protein 95 (PSD95, 1:100, Abcam); Growth associated protein 43 (GAP43, 1:1000, NOVUS Biologicals); SMI312 (1:100, Biolegend); Iba1 (1:1000, Wako); CD16/ 32 (1:800, BD Biosciences); CD206 (1:800, R\&D Systems), 5-Bromo-2'-Deoxyuridine (BrdU, 1:800, Abcam); CD31 (1:40, BD, Biosciences). The next day, slices were washed by PBS 3 times at 5-min intervals, and further incubated with corresponding secondary antibody (Alexa Fluor 488 or 594, Jackson Immuno Research, USA) for $1 \mathrm{~h}$. Finally, the nuclei were counterstained by Hoechst (1:100, Sigma-Aldrich, USA) for $15 \mathrm{~min}$. For BrdU staining, the slices were additionally denatured with $2 \mathrm{~N} \mathrm{HCl}$ at $37^{\circ} \mathrm{C}$ for $30 \mathrm{~min}$ and neutralized in $0.1 \mathrm{M}$ boric acid $(\mathrm{pH}$ 8.5) for 10 min before blocking with donkey serum albumin.

The number and intensity of Synaptophysin ${ }^{+}, \mathrm{PSD}^{+} 5^{+}$, $\mathrm{GAP}^{+} 3^{+}$, and $\mathrm{SMI}_{312}{ }^{+}$puncta were acquired using a confocal laser scanning microscope (Zeiss LSM880, German) and analyzed with MetaMorph software (Molecular Devices, v. 2.8.5) as described previously [4]. CD31positive blood vessels were highlighted using the ImageJ software; the area of CD31 positive blood vessels were automatically calculated by the software and expressed as the object area fraction of ROI [29]. Quantification of CD31-positive vessels was carried out by counting them in ROI as described previously [7]. The density of CD31positive vessels is expressed as the number of positive cells per $\mathrm{mm}^{2}$. Determination of the percentage of colabeled CD206 and Iba1 cells was achieved by counting the Iba1 ${ }^{+}$and co-labeled cells within the ROI using the ImageJ software. The percentage of co-labeled cells was calculated as: $(100 \% \times$ Total number of double positive cells/Total number of Iba $1^{+}$cells [29]. The percentage of co-labeled CD16/32 and Iba1 cells and co-labeled BrdU and CD31 cells were also determined in the same way. For each immunohistochemical staining item analysis, three sections were quantified and averaged per mouse, and each section contained three regions of interest in the peri-ischemic region.

\section{Enzyme-linked immunosorbent assay and Griess reaction}

Brains were harvested on days 14 or 21 after ischemic stroke and sectioned into seven 1-mm-thick coronal sections. Slices containing infarct were selected and then frozen on dry ice. For slices on day 14, the cortex tissues (about $15 \mathrm{mg}$ per mouse) were taken from the periinfract region; for slices on day 21, the cortex tissues were taken at the identical anatomical location as the slices on day 14. Specimens were homogenized in $450 \mu \mathrm{l}$ of extraction buffer per $15 \mathrm{mg}$ tissue wet weight. The tissue homogenates were centrifuged at $4^{\circ} \mathrm{C}$ for $20 \mathrm{~min}$ to remove the cellular debris, and then the supernatants were collected.

Tumor necrosis factor (TNF)- $\alpha$, interleukin (IL)- $1 \beta$, transforming growth factor (TGF)- $\beta$, and IL-10 in the supernatants collected from brain tissue or microglia culture were detected by ELISA (Cusabio Co., Ltd., Wuhan, China). The standard working curves were generated according to the concentration range of each cytokine. Production of nitric oxide (NO) was determined by measuring the content of Nitrite (the end products of $\mathrm{NO}$ ) in the media as previously described [15]. A standard Nitrite curve $(0.25-50 \mu \mathrm{M})$ was generated using a $10 \mathrm{mM}$ solution of $\mathrm{NaNO}$. All chemicals for the NO assay were from Sigma. Each sample was assayed in triplicate.

\section{Quantitative real-time polymerase chain reaction}

The total RNA of the sample was extracted by using a High-Capacity cDNA Archive Kit (Cat No.: 74804, QIAGEN). Extracted RNAs with OD260/280 values from 1.8 to 2.1 were qualified for subsequent experiments. One microgram of the total RNA was reverse-transcribed into cDNA using a Rapid Reverse Transcription Kit (Cat No.: 11752-250, Invitrogen). The corresponding primers (Invitrogen, Table 1) and $50 \mathrm{ng}$ cDNA were used to prepare PCR reaction solution with a fluorescent dye (RT2 SYBRr Green FAST Mastermixes, Cat No.: 330603, QIAGEN). qRT-PCR was performed in triplicate on a LightCycler 480 PCR machine (Applied Biosystemsr 7500 Real-Time PCR Systems, Thermo Fisher Scientific, Waltham, MA, USA) The thermal cycle parameters for qPCR were as follows: $95^{\circ} \mathrm{C}$ for $10 \mathrm{~min}$, followed by 40 cycles of $95^{\circ} \mathrm{C}$ for $15 \mathrm{~s}$, and $60^{\circ} \mathrm{C}$ for $20 \mathrm{~s}$, then $72^{\circ} \mathrm{C}$ for $20 \mathrm{~s}$. The fluorescent signal was collected at $72^{\circ} \mathrm{C}$ for 20 $\mathrm{s}$ in the third step of each cycle. The cycle time was normalized to GAPDH in the same sample. The levels of mRNAs were normalized to GAPDH in the same sample and then reported as fold changes vs. Sham group.

\section{Western blot}

Proteins were isolated using a total protein extraction kit from Apply gen Technologies Inc., (Beijing, China). The protein concentration was determined using a BCA Protein Assay reagent kit (Novagen, Madison, WI, USA). Equal amounts of protein $(100 \mu \mathrm{g})$ were separated by Tris-glycine SDS-PAGE and transferred to polyvinylidene fluoride (PVDF). The membranes were then incubated with blocking buffer (5\% nonfat dry milk) at room temperature for $1 \mathrm{~h}$ and incubated with the followed primary antibodies overnight at $4{ }^{\circ} \mathrm{C}$ : Rabbit polyclonal anti-GAPDH antibody (1:10000,Cell Signaling Technology, Danvers, MA, USA); Rabbit anti- $\beta$-catenin antibody (1:5000, Abcam); Mouse anti-GSK-3 $\beta$ antibody (1:1000, Abcam). Then, the membranes were incubated with the 
Table 1 Primers used for qRT-PCR

\begin{tabular}{lll}
\hline Primers & Forward $\left(5^{\prime}-3^{\prime}\right)$ & Reverse $\left(5^{\prime}-3^{\prime}\right)$ \\
\hline TNF-a & GATCTCAAAGACAACCAACTAGTG & CTCCAGCTGGAAGACTCCTCCCAG \\
CD16 & TTGGACACCCAGATGTTTCAG & GTCTTCCTTGAGCACCTGGATC \\
IL-6 & AGTTGCCTTCTTGGGACTGA & TCCACGATTTCCCAGAGAAC \\
iNOS & CAAGCACCTTGAAGAGGAG & AAGGCCAAACACAGCATACC \\
IL-1 $\beta$ & TGTCTTGGCCGAGGACTAAGG & TGGGCTGGACTGTTCTAATGC \\
IL-10 & CCAAGCCTTATCGGAAATGA & TाTCACAGGGGAGAAATCG \\
CD206 & CAAGGAAGGTTGGATTTGT & CCTTTCAGTCCTTGCAAGC \\
TGF- $\beta$ & TGCGCTTGCAGAGATTAAAA & CGTCAAAAGACAGCCACTCA \\
Arg-1 & TCACCTGAGCTTTGATGTCG & CTGAAAGGAGCCCTGTCTTG \\
YM1/2 & CAGGGTAATGAGTGGGTTGG & CACGGCACCTCCTAAATTGT \\
-Catenin & GCTGATTTGATGGAGTTGGA & GCTACTTGTTCTTGAGTGAA \\
GAPDH & AGGAGCGAGACCCCACTAACA & AGGGGGGCTAAGCAGTTGGT \\
\hline
\end{tabular}

Arg arginase, $C D$ cluster of differentiation, GAPDH glyceraldehyde-3-phosphate dehydrogenase, iNOS inducible nitric oxide synthase, IL interleukin, TGF transforming growth factor, TNF tumor necrosis factor

corresponding fluorescent labeling secondary antibody (1:8000, Rockland, Gilbertsville, PA, USA) for $1 \mathrm{~h}$ at room temperature. The relative density of each band was analyzed on an Odyssey infrared scanner (LICOR Bioscience, Lincoln, NE, USA). GAPDH was used as an internal control.

\section{Tube formation assay}

The bEnd. 3 cells $\left(2 \times 10^{4}\right.$ per well $)$ were seeded into 96well plates that were pre-coated with Matrigel (BD Biosciences Pharmingen, CA, USA). The 96-well plates were put in a chamber under normoxic condition for $12 \mathrm{~h}$. After incubation, the numbers of the capillary-like structures were quantified by the ImageJ software in randomly selected five microscopic fields from each well.

\section{CCK-8 assay}

Cell Counting Kit 8 (CCK8, Dojindo, Japan) was used to evaluate cytotoxicity as previously described [30]. In brief, cell suspensions $\left(1 \times 10^{4}\right.$ cells, $100 \mu \mathrm{l} /$ well $)$ were seeded in a 96-well plate. Then, $10 \mu$ of the CCK- 8 reagent was added into each well, followed by $2 \mathrm{~h}$ of incubation at $37^{\circ} \mathrm{C}$. The reaction was evaluated according to the absorbance at $450 \mathrm{~nm}$.

\section{Flow cytometry}

Flow cytometry was used to detect the expression of CD16/32 and CD206 in microglia cells as previously described [31]. In brief, $100 \mu \mathrm{l}$ microglia cell suspension (1 $\times 10^{6}$ cells) was aliquoted into $1 \mathrm{ml}$ Eppendorf tubes. The anti-mouse CD16/32 PE (0.125 $\mu$ g, Biolegend, CA, USA) and anti-mouse CD206 (MMr) FITC $(0.125 \mu \mathrm{g}$, Biolegend, CA, USA) were added into the EP tubers after $0.5 \mathrm{~h}$ of incubation at $4{ }^{\circ} \mathrm{C}$, The microglia cells were washed with PBS twice and resuspended in $300 \mu \mathrm{l} 1 \times$
PBS solution. Analyses were performed on BectonDickinson FACS Calibur (Becton Dickinson, Bedford, MA). Mean fluorescence intensity was measured.

\section{Statistical analysis}

All outcome analysis was carried out by independent researchers blinded to the information of experimental groups. All data were presented as mean \pm standard error of the mean (SEM) with the exception of the mNSS data, which were expressed as median \pm interquartile range (IQR). Statistical analyses were performed using SPSS21.0 software (Version X, IBM, Armonk, NY, USA). Comparisons between two groups were evaluated using Student's $t$ test (non-directional). Comparisons between multiple groups were analyzed with one-way or two-way analysis of variance (ANOVA) followed by Tukey's post hoc test, unless otherwise indicated. The data of mNSS were assessed using the Mann-Whitney rank-sum test. The Spearman or correlation was also determined. All analyses were two-tailed, and $P<0.05$ was considered statistically significant.

\section{Results}

TWS119 improved post-stroke neurological function

CatWalk test, Adhesive Removal test, Accelerated Rotarod test, and mNSS were selected to assess neurological function. TWS119-treated mice performed better in swing speed $(41.86 \pm 1.90$ versus $58.80 \pm 2.92 \mathrm{~cm} / \mathrm{s}, P<0.001$; $44.93 \pm 2.86$ versus $69.90 \pm 2.42 \mathrm{~cm} / \mathrm{s}, P<0.001$, Fig. $2 \mathrm{a})$, stride length $(5.02 \pm 0.13$ versus $5.65 \pm 0.12 \mathrm{~cm}, P<0.01$; $5.10 \pm 0.13$ versus $5.98 \pm 0.11 \mathrm{~cm}, P<0.001$, Fig. $2 \mathrm{~b})$ and paw intensity $(64.56 \pm 2.17$ versus $73.82 \pm 1.70, P<0.01$; $70.21 \pm 1.46$ versus $79.13 \pm 2.13, P<0.01$, Fig. $2 c)$ of the left front limb compared with vehicle mice at days 14 and 21 after stroke, suggesting an improvement in gait 

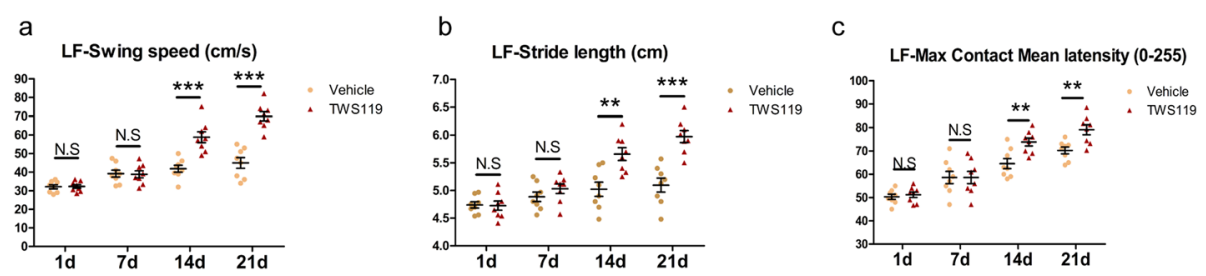

d
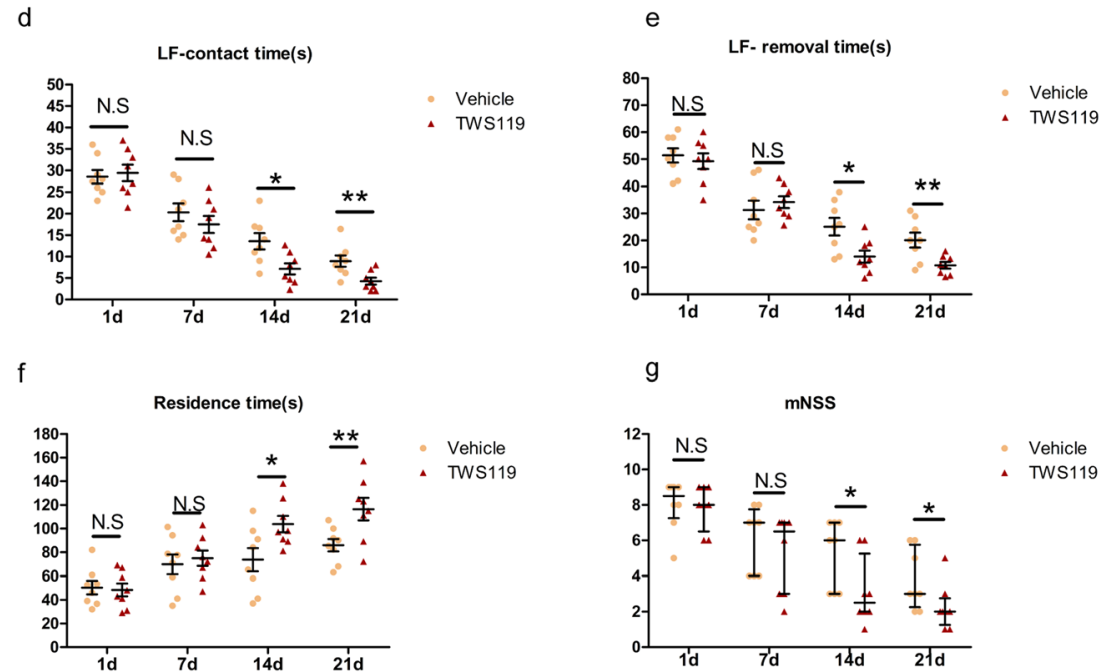

Fig. 2 TWS119 improved post-stroke neurological function. CatWalk test (a-c), Adhesive Removal test (d, e), Accelerated Rotarod test (f) and mNSS (g) were performed between vehicle group and TWS119 group at day 1, 7, 14 and 21 after stroke. a-e TWS119 treatment, as opposed to saline injection, accelerated LF functional recovery. $\mathbf{f}$ TWS1 19 mice displayed better performance in Accelerated Rotarod test compared with vehicle mice. $\mathbf{g}$ TWS119 mice had lower mNSS compared with vehicle mice. LF, left forelimb, mNSS, modified neurological severity scores. $(n=8$ per group, ${ }^{*} P<0.05,{ }^{* *} P<0.01,{ }^{* *} P<0.001, \mathrm{~N} . \mathrm{S}=$ no statistical difference)

performance attributed to TWS119 treatment. Adhesive Removal test showed TWS119 treatment reduced the contact time $(13.58 \pm 1.88$ versus $7.15 \pm 1.29 \mathrm{~s}, P<0.05$; $8.96 \pm 1.33$ versus $4.29 \pm 0.80 \mathrm{~s}, P<0.01$, Fig. $2 \mathrm{~d}$ ) and removal time $(25.11 \pm 3.28$ versus $14.04 \pm 6.26 \mathrm{~s}, P<0.05$; $20.12 \pm 2.76$ versus $10.80 \pm 1.22 \mathrm{~s}, P<0.01$, Fig. 2 e) in ischemic mice compared with saline treatment at days 14 and 21 after stroke, indicating TWS119 improved poststroke sensorimotor function and postural asymmetry. Consistently, TWS119-treated mice displayed better motor coordination and learning function than vehicle mice in Accelerated Rotarod test at days 14 and 21 after stroke $(73.74 \pm 9.81$ versus $103.92 \pm 6.94 \mathrm{~s}, P<0.05 ; 82.17$ \pm 5.97 versus $116.25 \pm 9.49 \mathrm{~s}, P<0.01$, Fig. 2 f). As expected, compared with the vehicle group, mice in TWS119 group displayed lower mNSS at days 14 and 21 after stroke $(Z=-2.27, P=0.023 ; Z=-2.07, P=0.038$, Fig. 2 g). Collectively, the behavioral data suggested that TWS119 significantly promoted neurological recovery in the late phase of ischemic stroke. Additionally, TWS119 enhanced the level of $\beta$-catenin via inhibiting GSK-3 $\beta$ at day 14 after stroke and mitigated the histological damage of focal cerebral ischemic mouse at day 21 after stroke (see Supplementary Figure 2S, Additional file 1).

\section{TWS119 facilitated post-stroke angiogenesis and neural plasticity}

Neurovascular restoration is a multi-element exquisitely coordinated process, including angiogenesis and neural plasticity. The angiogenesis and neural plasticity were closely correlated with functional recovery following stroke [5]. To clarify the role of TWS119 on post-stroke angiogenesis, the expression of CD31 (cerebral microvascular endothelial cells marker) and BrdU (cell proliferation marker) were detected by immunofluorescence staining [32]. Compared with sham-operated mice, the vehicle mice displayed an elevation in area $(3.91 \% \pm$ $0.52 \%$ versus $7.05 \% \pm 0.77 \%, P<0.01 ; 5.88 \% \pm 0.66 \%$ versus $8.90 \% \pm 0.84 \%, P<0.05$, Fig. $3 \mathrm{~b})$ and density $\left(58.06 \pm 8.23\right.$ versus $93.54 \pm 10.53$ cells $/ \mathrm{mm}^{2}, P<0.05$; $69.71 \pm 11.94$ versus $120.64 \pm 10.56$ cells $/ \mathrm{mm}^{2}, P<0.05$, Fig. 3c) of CD31-positive vessels at days 14 and 21 after stroke. Interestingly, TWS119 treatment significantly enhanced the area $(8.90 \% \pm 0.84 \%$ versus $13.78 \% \pm 1.12 \%$, $P<0.01$, Fig. 3b) at day 21 after stroke, and the density $\left(93.54 \pm 10.53\right.$ versus $121.46 \pm 8.15$ cells $/ \mathrm{mm}^{2}, P<0.05$; $120.64 \pm 10.56$ versus $160.46 \pm 8.15$ cells $/ \mathrm{mm}^{2}, P<0.05$, Fig. 3c) of CD31-positive vessels at days 14 and 21 in ischemic mice compared with saline treatment. Moreover, 


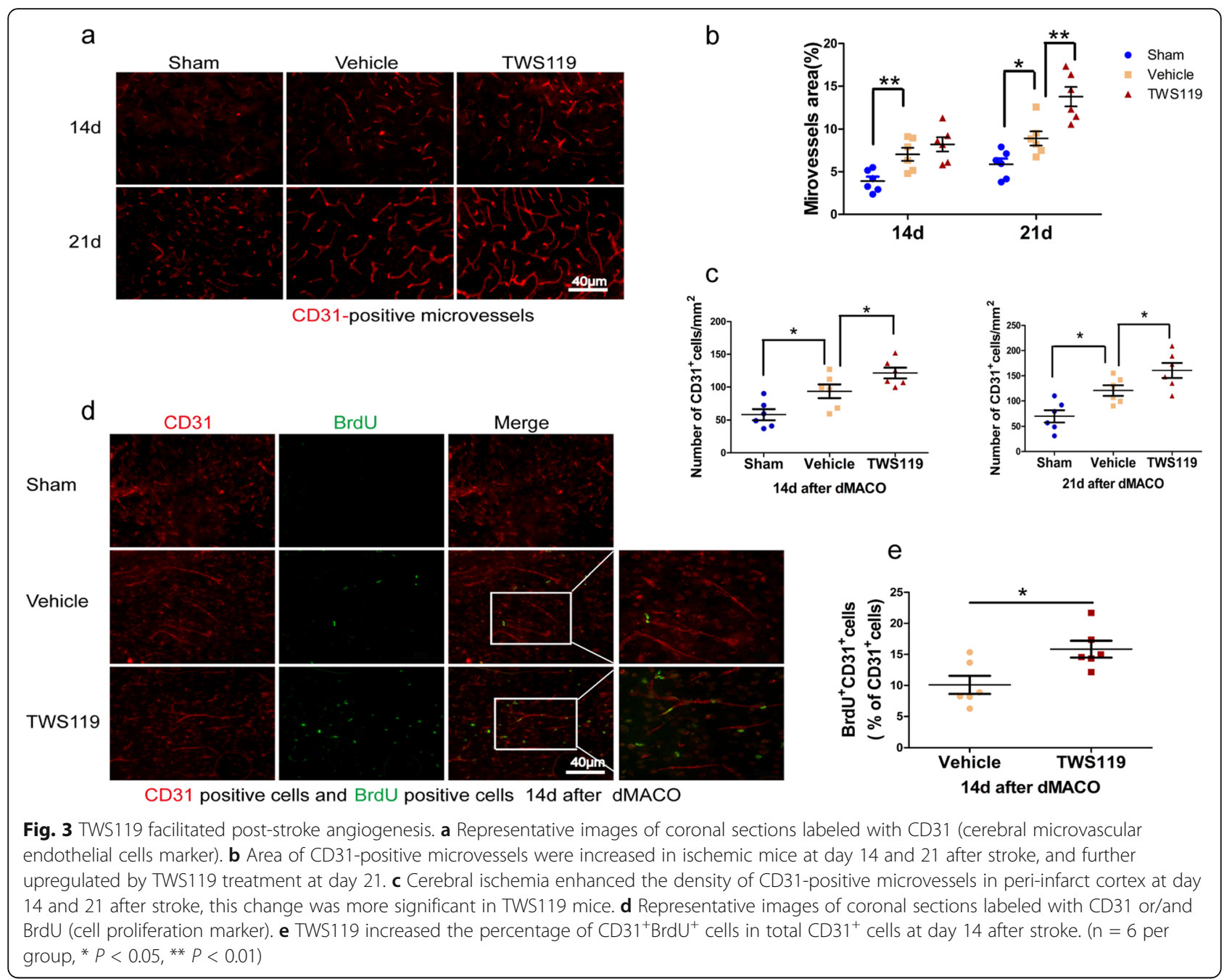

a significant increase of $\mathrm{BrdU}^{+} / \mathrm{CD} 31^{+}$cells was detected in TWS119 mice compared with those in vehicle mice $(10.10 \% \pm 1.46 \%$ versus $15.85 \% \pm 1.35 \%, P<0.05$, Fig. $3 e)$. Collectively, the results indicated that TWS119 facilitated angiogenesis in the chronic phase of stroke.

To further explore the effect of TWS119 on poststroke neural plasticity, the expression of GAP43 (a marker of post-stroke axonal, synaptic and glial plasticity), PSD95 (a marker for postsynaptic plasticity and synaptogenesis), Synaptophysin (a marker for presynaptic plasticity and synaptogenesis) and SMI312 (a marker of Neurofilament) in peri-infarct cortex were also quantified by immunohistochemistry at day 21 after stroke [4]. Compared with the vehicle group, the density of $\mathrm{GAP} 3^{+}$puncta $\left(2.54 \times 10^{4} \pm 0.12 \times 10^{4}\right.$ versus $3.34 \times$ $10^{4} \pm 0.42 \times 10^{4}$ puncta/ $\mathrm{mm}^{2}, P<0.01$, Fig. $\left.4 \mathrm{~b}\right)$, PSD $95^{+}$ puncta $\left(4.01 \times 10^{4} \pm 0.23 \times 10^{4}\right.$ versus $4.97 \times 10^{4} \pm 0.29$ $\times 10^{4}$ puncta $/ \mathrm{mm}^{2}, P<0.05$, Fig. $\left.4 \mathrm{c}\right)$, SMI312 $2^{+}$puncta $\left(2.32 \times 10^{4} \pm 0.12 \times 10^{4}\right.$ versus $3.11 \times 10^{4} \pm 0.15 \times 10^{4}$ puncta $/ \mathrm{mm}^{2}, P<0.01$, Fig. 4e) and Synaptophysin ${ }^{+}$ puncta $\left(4.51 \times 10^{4} \pm 0.26 \times 10^{4}\right.$ versus $5.87 \times 10^{4} \pm 0.48 \times$ $10^{4}$ puncta $/ \mathrm{mm}^{2}, P<0.01$, Fig. $4 \mathrm{f}$ ) were increased in TWS119-treated mice, indicating that TWS119 stimulated post-stroke neural plasticity, which was consistent with the pro-angiogenic effect of TWS119.

\section{TWS119 modulated microglia/macrophages to an anti-} inflammatory phenotype following ischemic stroke Activated microglia alter dynamically between two functional polarization, namely pro-inflammatory phenotype and anti-inflammatory phenotype. Pro-inflammatorytype microglia display upregulation of CD16 (Fc receptors), TNF- $\alpha$, iNOS, IL-1 $\beta$, and IL-6, whereas antiinflammatory-type microglia are characterized by upregulation of CD206 (mannose receptor), IL-10, TGF- $\beta$, Arg-1, and Ym1/2 (chitinase3-like 3). To explore the effect of TWS119 on the polarization of microglia, proinflammatory/anti-inflammatory phenotype signature genes $[8,22]$ were examined by qRT-PCR at day 14 after stroke (Fig. 5a). The mRNA expressions of CD16 (0.99 \pm 


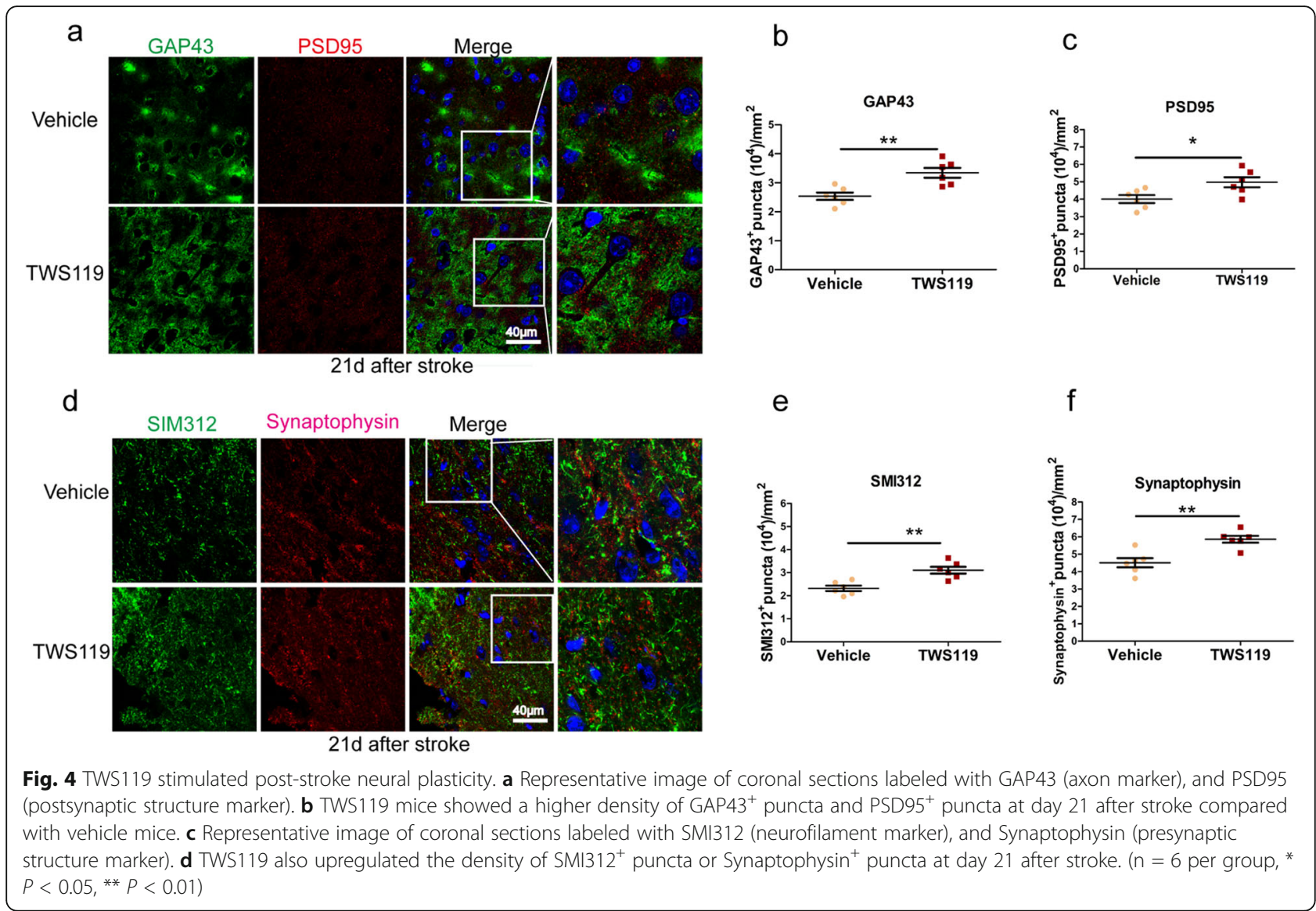

0.10 versus $6.81 \pm 0.88, P<0.01)$, TNF- $\alpha(1.03 \pm 0.13$ versus $5.75 \pm 0.73, P<0.01)$, iNOS $(0.94 \pm 0.06$ versus $20.96 \pm 1.59, P<0.001)$, IL-1 $\beta(0.94 \pm 0.10$ versus $4.06 \pm$ $0.35, P<0.001)$, IL-6 $(0.93 \pm 0.74$ versus $8.93 \pm 1.10, P<$ $0.01)$ and CD206 (0.99 \pm 0.13 versus $1.57 \pm 0.17, P<$ $0.05)$ were upregulated in vehicle mice compared with sham-operated mice. TWS119 treatment significantly reduced the expressions of CD16 (6.81 \pm 0.88 versus $3.34 \pm$ $0.39, P<0.05)$, TNF-a $(5.75 \pm 0.73$ versus $1.98 \pm 0.43, P<$ $0.01)$ and iNOS (20.96 \pm 1.59 versus $13.58 \pm 0.68, P<0.05)$, upregulated the expressions of CD206 (1.57 \pm 0.17 versus $2.49 \pm 0.24, P<0.01)$, IL-10 (2.27 \pm 0.49 versus $6.94 \pm 0.80$, $P<0.01)$, TGF- $\beta(0.74 \pm 0.08$ versus $1.10 \pm 0.14, P<0.05)$, Arg-1 (0.81 \pm 0.14 versus $4.56 \pm 0.62, P<0.01)$, and YM1/2 $(0.95 \pm 0.11$ versus $1.85 \pm 0.31, P<0.01)$ in ischemic mice compared with saline treatment. Apart from qRT-PCR, immunofluorescence staining was further used to confirm the effect of TWS119 on modulating microglial polarization. CD16/32 (pro-inflammatory phenotype marker) and CD206 (anti-inflammatory phenotype marker) and Iba-1 (microglia/macrophages marker) were analyzed by double immunofluorescent staining as previously described [22]. Compared with vehicle mice, TWS119 mice showed a reduced ratio of CD16/32 $2^{+} \mathrm{Iba}-1^{+}$cells at day14 after stroke $(26.93 \% \pm 1.77 \%$ versus $17.72 \% \pm 2.05 \%, P<0.01$, Fig. $5 c)$ and an increased proportion of $\mathrm{CD} 206^{+} \mathrm{Iba}-1^{+}$cells at days 14 and 21 after stroke $(26.69 \% \pm 1.96 \%$ versus $33.49 \% \pm$ $1.88 \%, P<0.05 ; 11.81 \% \pm 1.08 \%$ versus $18.13 \% \pm 1.71 \%, P<$ 0.05, Fig. 5e). Together, the results of qRT-PCR and Immunofluorescence suggested that TWS119 promoted poststroke microglia/macrophages to the anti-inflammatory phenotype.

\section{TWS119 ameliorated local inflammatory} microenvironment in peri-infarct cortex

Microglia contributes to the alteration of the inflammatory microenvironment via secretion of cytokines. To explore the effect of TWS119 on the local inflammatory microenvironment, pro-inflammatory cytokines (TNF- $\alpha$ ), and anti-inflammatory cytokine (IL-10) in peri-infarct cortex were detected using ELISA (Fig. 6a). Compared with sham-operated mice, the productions of TNF- $\alpha$ (28.64 \pm 3.03 versus $81.42 \pm 8.73 \mathrm{pg} / \mathrm{mg}$ protein, $P<0.001 ; 28.48 \pm$ 2.22 versus $57.99 \pm 3.14 \mathrm{pg} / \mathrm{mg}$ protein, $P<0.001$ ) were obviously increased in $\mathrm{dMACO}$ mice with saline treatment at days 14 and 21 after stroke. TWS119 treatment significantly reduced the TNF- $\alpha(81.42 \pm 8.73$ versus $48.13 \pm 6.13 \mathrm{pg} / \mathrm{mg}$ protein, $P<0.01)$ in ischemic mice compared with saline treatment at day 14 after stroke and increased IL-10 (21.11 \pm 2.67 versus $45.93 \pm 6.11 \mathrm{pg} / \mathrm{mg}$ 


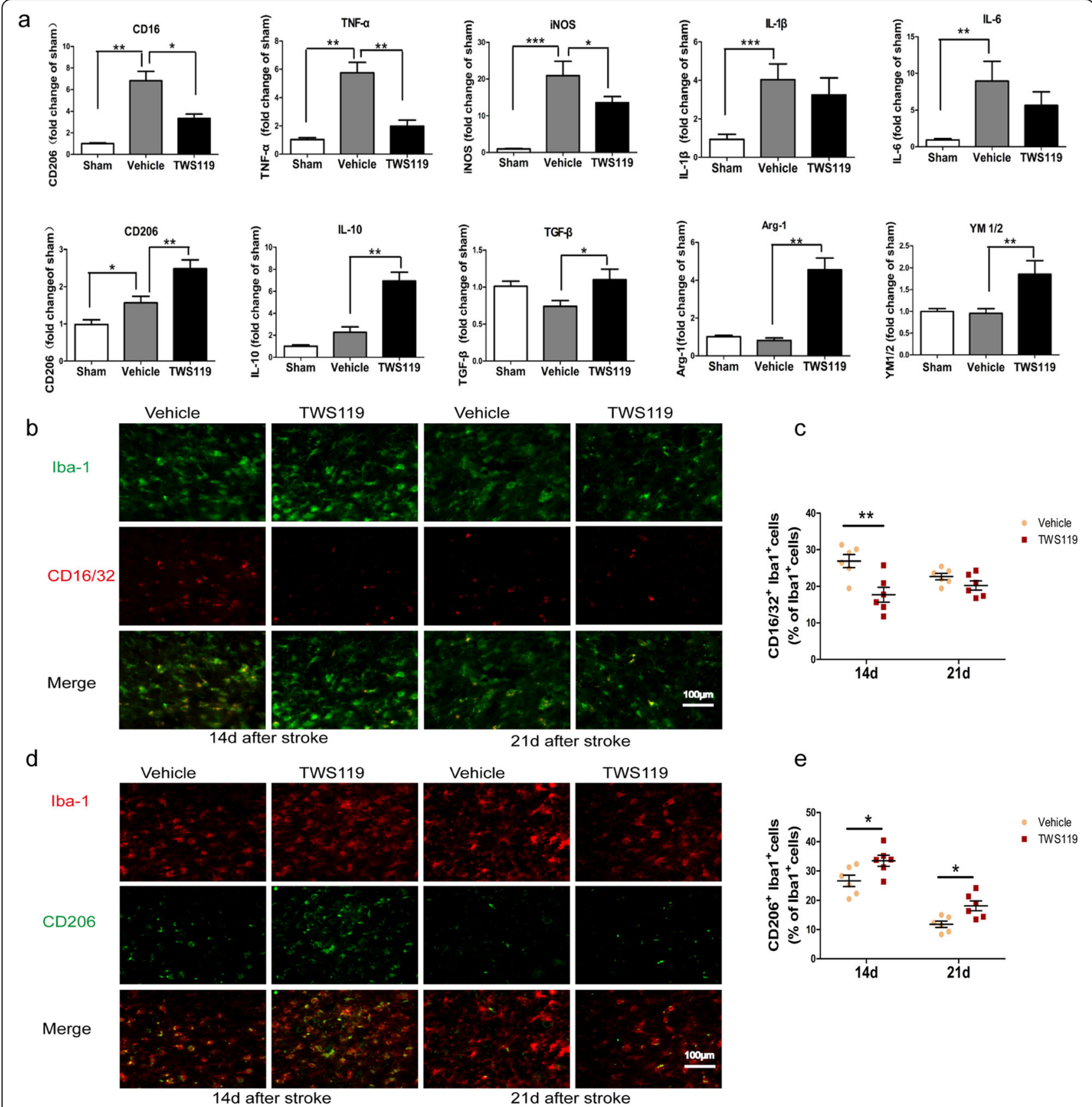

Fig. 5 TWS119 modulated microglia/Macrophages to anti-inflammatory phenotype after ischemic stroke. a Pro-inflammatory-type marker (CD-16, TNF- $\alpha$, iNOS, IL-1 $\beta$ and IL-6) and anti-inflammatory-type marker (CD206, IL-10, TGF- $\beta$, Arg-1 and YM1/2) of microglia were analyzed by qRT-PCR 14 days after stroke. The mRNA levels of CD-16, TNF- $\alpha$, iNOS, IL-1 $\beta$, IL-6 and IL-10 were increased in vehicle mice compared with sham mice, TWS119 treatment decreased the level of CD-16, TNF- $\alpha$ and iNOS, and upregulated the level of CD206, IL-10, TGF- $\beta$, Arg-1 and YM1/2 compared with saline treatment. b Representative images of coronal sections labeled with Iba1 (microglia marker), and CD16/32. c TWS119 reduced the ratio of $\mathrm{CD} 16 / 32^{+} \mathrm{Iba} 1^{+}$cells at 14 days after stroke. $\mathbf{d}$ Representative images of coronal sections labeled with Iba1, and CD206. e TWS119 increased the ratio of $\mathrm{CD} 206^{+} \mid \mathrm{ba} 1^{+}$cells at 14 and 21 days after stroke. $\left(\mathrm{n}=6\right.$ per group, $\left.{ }^{*} P<0.05,{ }^{* *} P<0.01\right)$

protein, $P<0.05$ and $17.53 \pm 1.80$ versus $44.40 \pm 4.82 \mathrm{pg} /$ mg protein, $P<0.01$ ) at days 14 and 21 after stroke, indicating an amelioration of local inflammatory microenvironment mediated by TWS119 in peri-infarct cortex. To further explore whether the amelioration of the local inflammatory microenvironment was involved in neurological improvement, Correlation analyses were performed between the data of the IL-10 and the data of some neurobehavioral test (Fig. 6b). There was a positive correlation between the concentration of IL-10 and the residence time 

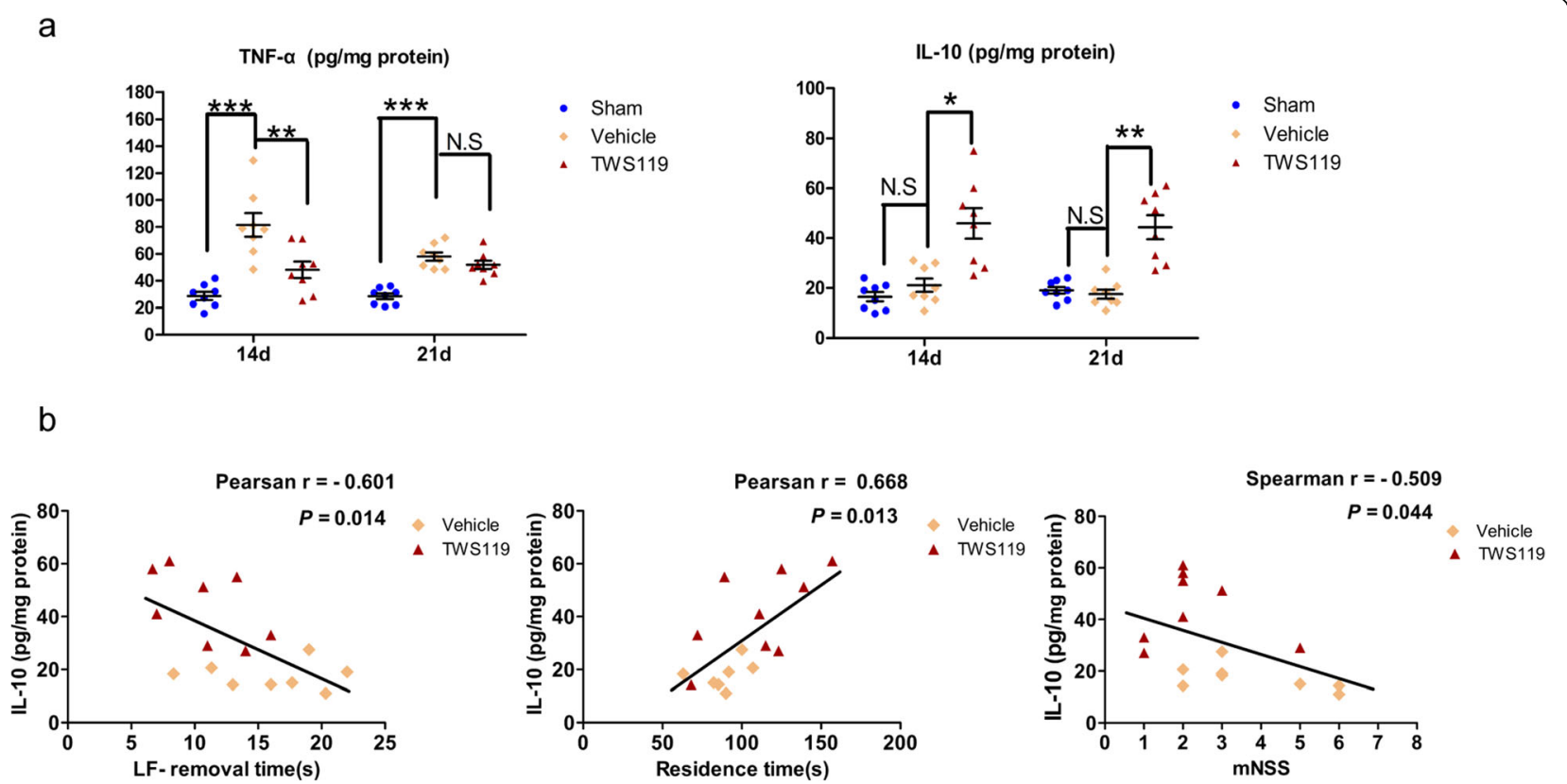

Fig. 6 TWS119 ameliorated local inflammatory microenvironment in peri-infarct cortex. a TNF-a (pro-inflammatory cytokine) and IL-10 (antiinflammatory cytokine) in per-infarct region ware measured by ELISA. The production of TNF-a was obviously increased at day 14 and 21 after stroke. TWS119 significantly reduced the production of TNF-a at day 14, and increased the production of IL-10 at day 14 and 21 . b The production of IL-10 had a positive correlation with the residence time of Accelerated Rotarod test, while the production of IL-10 had a negative correlation with the LF-removal time in Adhesive Removal test and the mNSS at day 21 after stroke. LF, left forelimb; mNSS, modified neurological severity scores. $\left(\mathrm{n}=8\right.$ per group, $\left.{ }^{*} P<0.05,{ }^{*} P<0.01\right)$

of Accelerated Rotarod test at day 21 after stroke $(r=0.668$, $P=0.013)$. IL-10 had a negative correlation with the LFremoval time of Adhesive Removal test $(r=-0.601, P=$ $0.014)$ and the mNSS $(r=-0.509, P=0.044)$ respectively at day 21 after stroke, suggesting a close correlation between local inflammatory status and neurological improvement in the chronic phase of stroke.

TWS119 promoted pro-inflammatory to anti-inflammatory phenotype switch of microglia probably via the Wnt/ $\beta$ catenin pathway in vitro

Primary microglia were used to further determine the modulating effect of TWS119 on microglial polarization and elucidate the underlying role of Wnt/ $\beta$-catenin pathway in this. Pro-inflammatory polarized microglia were induced by LPS plus IFN- $\gamma$ stimulation in vitro. Firstly, we selected the effective dose of TWS119 in microglia. CCK-8 assay was performed to determine the cytotoxicity of TWS119; TWS119 with doses $(\geq 100 \mu \mathrm{M})$ exerted cytotoxic effect on microglia cells (Fig. 7a). TWS119 with doses $(10 \mu \mathrm{M}, 20 \mu \mathrm{M})$ increased the secretion of IL-10 in microglia cells stimulated with LPS $+\operatorname{IFN}-\gamma(P=0.002 ; P=$ 0.001 , Fig. 7b), while TWS119 with doses $(5 \mu \mathrm{M}, 40 \mu \mathrm{M})$ had no similar effect. TWS119 at the dose of $10 \mu \mathrm{M}$ is widely used in other cell lines [33, 34], Thus, the dose $(10 \mu \mathrm{M})$ was used in our experiment in vitro. The dose $(10 \mu \mathrm{M})$ of IWR-1 used in microglia cells was according to previous research $[15,35]$. Next, qRT-PCR was used to characterize the polarization of microglia cells (Fig. 7c). The mRNA level of CD16 was drastically upregulated in microglia cells stimulated by LPS plus IFN- $\gamma$ compared with the control $(1.02 \pm 0.18$ versus $4.83 \pm 0.64, P<$ $0.001)$, TWS119 treatment significantly attenuated this alteration of CD16 ( $4.83 \pm 0.64$ versus $2.49 \pm 0.39, P<0.01)$ and increased the mRNA expression of CD206 (0.89 \pm 0.16 versus $2.10 \pm 0.31, P<0.01$ ) in microglia cells stimulated by LPS plus IFN- $\gamma$. TWS119 plus IWR-1 treatment increased the level of CD16 (2.49 \pm 0.39 versus $4.09 \pm$ $0.39, P<0.05)$ and reduced the level of CD206 (2.10 \pm 0.31 versus $1.32 \pm 0.22, P<0.05)$ in microglia cells stimulated by LPS plus IFN- $\gamma$ compared with TWS119 treatment. Consistently, flow cytometry (Fig. 7d) showed that TWS119 reduced the percentage of CD16/32 positive cells $(38.74 \% \pm 3.10 \%$ versus $18.10 \% \pm 3.80 \%, P<0.01)$ and increased the percentage of CD206 positive cells $(12.25 \% \pm$ $2.23 \%$ versus $30.33 \% \pm 6.04 \%, P<0.01)$ in microglia cells with LPS plus IFN- $\gamma$ stimulation, indicating a direct modulating effect of TWS119 on switch of microglial polarization from pro-inflammatory phenotype to antiinflammatory phenotype. This effect was reversed by IWR-1 $(18.10 \% \pm 3.80 \%$ versus $33.97 \% \pm 4.36 \%, P<0.05$; $30.33 \% \pm 6.04 \%$ versus $16.70 \% \pm 2.60 \%, P<0.05)$. Finally, the expression of $\beta$-catenin, the key molecule of $\mathrm{Wnt} / \beta$ catenin signaling, was investigated using western blot and 


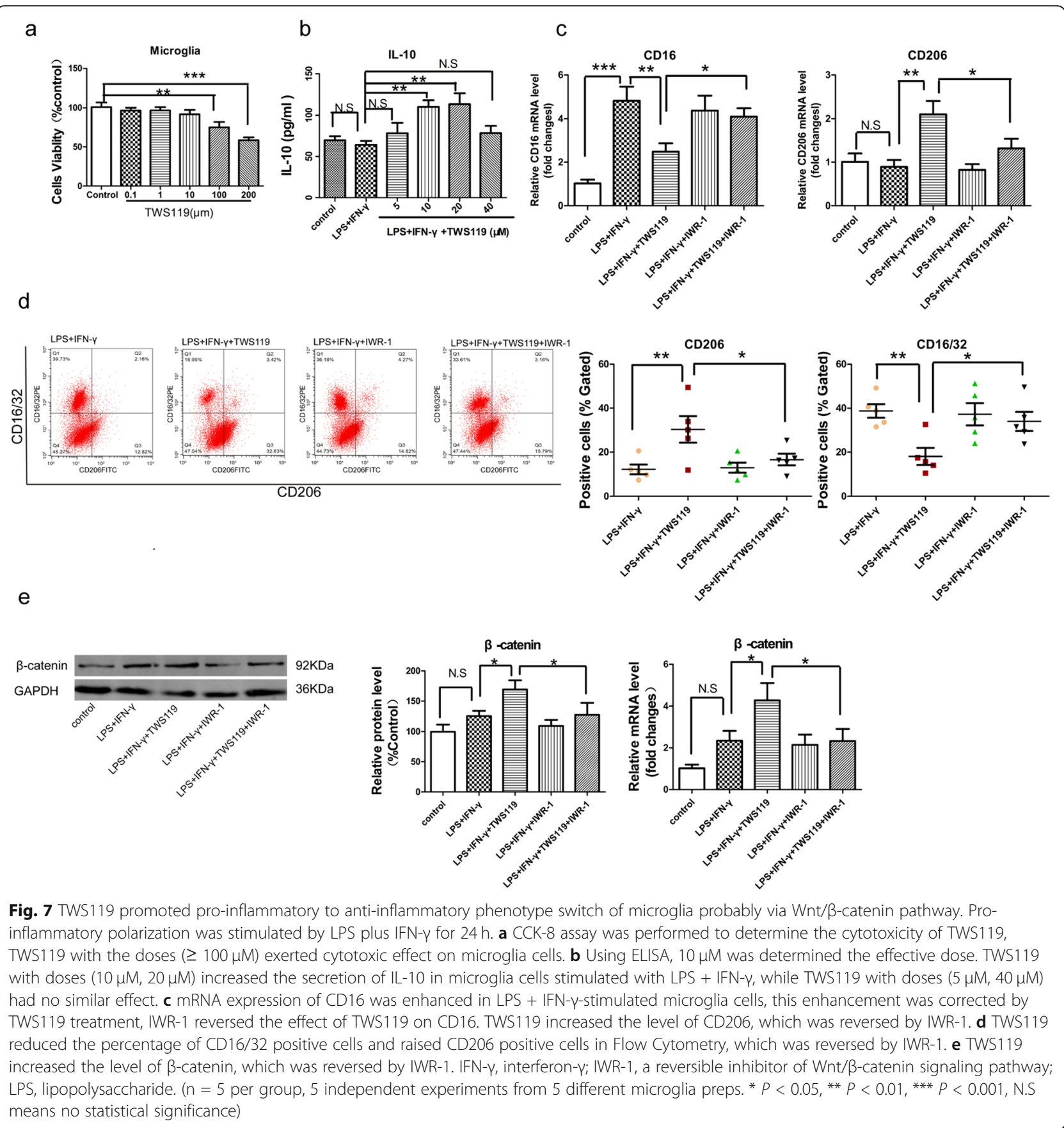

qRT-PCR (Fig. 7e). TWS119 treatment increased the protein expression and mRNA expression of $\beta$-catenin in microglia cells stimulated by LPS plus IFN- $\gamma(125.64 \% \pm$ $19.23 \%$ versus $169.00 \% \pm 15.41 \%, P<0.05, P<0.05 ; 2.35 \pm$ 0.47 versus $4.27 \pm 0.83, P<0.05)$. indicating a TWS119induced activation of $\mathrm{Wnt} / \beta$-catenin signaling pathway. IWR-1 reversed the effect of TWS119 on enhancing $\beta$ catenin in microglia cells stimulated by LPS plus IFN- $\gamma$ $(169.00 \% \pm 15.41 \%$ versus $127.67 \% \pm 19.39 \%, P<0.05 ; 4.27$ \pm 0.83 versus $2.33 \pm 0.72, P<0.05)$.
TWS119 promoted angiogenesis in vitro via an amelioration of inflammatory microenvironment by altering microglia polarization

The bEnd. 3 cell line was used to explore the underlying mechanism on the effect of TWS119 on promoting post-stroke angiogenesis. OGD injury was mimicked cerebral ischemic injury. Tube formation assay was used to assess angiogenesis in vivo. Using conventional medium, the capillary-like tube formation in OGD bEnd. 3 cells were decreased compared with bEnd.3 cells 
$(36.20 \pm 6.01$ versus $20.16 \pm 2.41, P<0.05$, Fig. 8 a); this decrease was not effectively corrected by TWS119 treatment $(20.16 \pm 2.41$ versus $25.27 \pm 3.66, P=0.416$, Fig. $8 \mathrm{a})$, indicating that TWS119 failed to directly promote angiogenesis in vitro, which was inconsistent with our result in vivo. Considering the favorable effect of TWS119 on microglial polarization, we speculated TWS119 might facilitate angiogenesis through modulating switch of microglial polarization from pro-inflammatory phenotype to anti-inflammatory phenotype in vitro. To directly address this hypothesis, we determined the response of tube formation of OGD bEnd.3 cells in conditioned medium (CM) collected from supernatants of each microglia group $[7,8]$. Firstly, proinflammatory cytokines (TNF- $\alpha$, IL- $1 \beta$, and Nitrite) and anti-inflammatory cytokines (IL-10 and TGF- $\beta$ ) in each CM were detected (Fig. 8b). The secretion

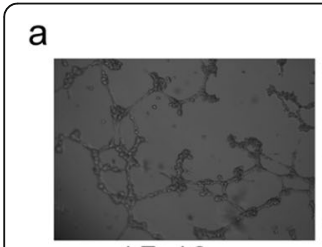

bEnd.3

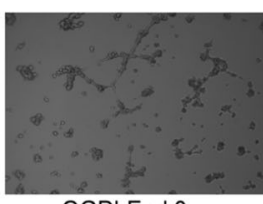

OGDbEnd.3

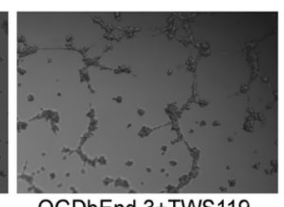

OGDbEnd.3+TWS119

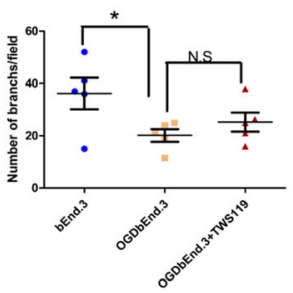

b
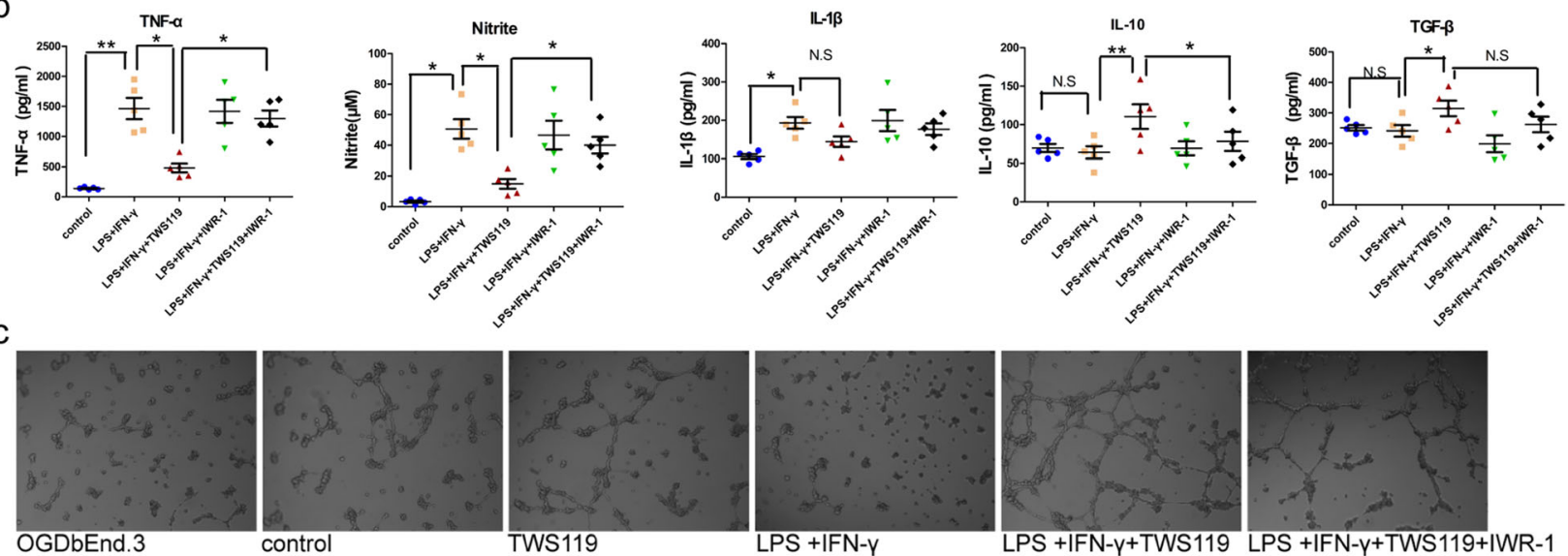

OGDbEnd.3s in Conditioned Medium

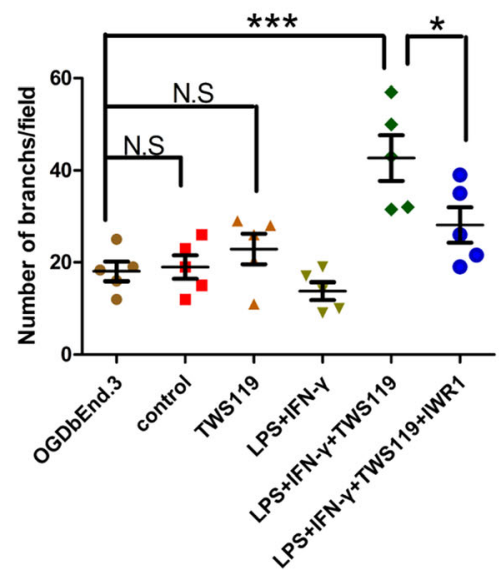

Fig. 8 TWS119 promoted angiogenesis in vitro via an amelioration of inflammatory microenvironment by altering microglia polarization. a Tube formation of bEend3 cells in conventional medium $(5 \times$ magnification). OGD injury reduced vascular tubular structures, which was not corrected by TWS119 treatment. b Supernatants of each microglia culture were used as CM. Proinflammatory cytokines (TNF-a, Nitrite, IL-1 $\beta$ ) and antiinflammatory cytokines (IL-10, TGF- $\beta$ ) were detected in each CM. c Representative images of tube formation in OGDbEend. 3 cells incubated with CM $(5 \times$ magnification). Interestingly, only CM co-treated with LPS plus IFN- $\gamma$ and TWS119 significantly increased the formation of pro-angiogenic structures in OGDbEnd.3 cells. Other CM had no similar function. bEend3, mouse-derived brain microvascular cell line; IFN- $\gamma$, interferon- ${ }^{\text {; }}$ CM, conditioned media; LPS, lipopolysaccharide; OGD, oxygen-glucose deprivation. ( $n=5$, ${ }^{*} P<0.05$, ${ }^{* *} P<0.05$, N.S means no statistical significance) 
of TNF- $\alpha(139.33 \pm 9.02$ versus $1461.80 \pm 176.12 \mathrm{pg} / \mathrm{ml}, P<$ $0.01)$, Nitrite $(3.30 \pm 0.65$ versus $50.66 \pm 6.37 \mu \mathrm{M}, P<0.05)$ and IL-1 $\beta(105.54 \pm 6.18$ versus $193.14 \pm 15.22 \mathrm{pg} / \mathrm{ml}, P<$ 0.01 ) were increased in LPS+IFN- $\gamma$ CM compared with the control CM. The productions of TNF- $\alpha(1461.80 \pm 176.12$ versus $480.38 \pm 73.24 \mathrm{pg} / \mathrm{ml}, P<0.05)$ and Nitrite $(50.66 \pm$ 6.37 versus $14.93 \pm 3.18 \mu \mathrm{M}, P<0.05)$ were decreased, while the productions of IL-10 $(64.04 \pm 15.95$ versus $110.41 \pm$ $9.11 \mathrm{pg} / \mathrm{ml}, P<0.01)$ and TGF- $\beta(241.35 \pm 18.94$ versus $314.86 \pm 25.38 \mathrm{pg} / \mathrm{ml}, P<0.05)$ were increased in LPS+IFN$\gamma+$ TWS119 CM compared with LPS+IFN- $\gamma$ CM, indicating TWS119 improved inflammatory microenvironment in CM by attenuating proinflammatory cytokines and upregulating anti-inflammatory cytokines, which was consistent with the promoting effect of TWS119 on switch of microglial polarization from pro-inflammatory phenotype to antiinflammatory phenotype. Next, OGD bEnd.3 cells were incubated with $\mathrm{CM}$ for $12 \mathrm{~h}$ (Fig. 8c). Control CM did not promote the formation of pro-angiogenic structures in OGD bEnd. 3 cells $(18.07 \pm 2.12$ versus $18.99 \pm 2.25, P=$ 0.845). Control CM with direct addition of TWS119 (18.07 \pm 2.12 versus $22.89 \pm 3.32, P=0.312)$ and $C M$ stimulated with LPS plus IFN- $\gamma(18.07 \pm 2.12$ versus $13.81 \pm 1.93, P=$ 0.371 ) failed to form pro-angiogenic structures in OGD bEnd.3 cells. Interestingly, CM co-treated with LPS plus IFN- $\gamma$ and TWS119 significantly increased the formation of pro-angiogenic structures in OGD bEnd.3 cells (18.07 \pm 2.12 versus $42.71 \pm 4.98, P<0.001$ ), suggesting that the proangiogenic effect of TWS119 was likely attributed to modulating microglial polarization instead of the direct effect on vascular endothelial cells damaged by cerebral ischemia. As expected, IWR-1 reversed this indirect pro-angiogenic effect of TWS119 (42.71 \pm 4.98 versus $28.11 \pm 3.85, P<0.01)$.

\section{Discussion}

The limited neurorestorative capability contributes to long-term neurological deficits following ischemic stroke, which markedly impair the quality of a patient's daily life. The present study demonstrated that the Wnt canonical pathway activator TWS119 exhibits significant efficacy in the improvement of neurological function following experimental stroke, paralleled by an acceleration of angiogenesis and neural plasticity in the peri-infarct cortex. The underlying mechanism for the neurorestorative effect of TWS119 was probably due to $\beta$-catenin-mediated shift of microglia polarization from pro-inflammatory phenotype to anti-inflammatory phenotype.

An independent study [17] reported that intraperitoneal injection of TWS119 at $3.5 \mathrm{~h}$ decreased neurologic deficits, brain edema, infarct volume, and blood-brain barrier permeability at $24 \mathrm{~h}$ after stroke via activation the $\mathrm{Wnt} / \beta$-catenin pathway in the ischemia-reperfusion rat model. To distinguish neuroprotective from neurorestorative effect on long-term neurological function,
TWS119 was administered in a delayed manner in the current study. TWS119-treated mice displayed comprehensive improvement in long-term neurological function, including gait performance, sensorimotor function, postural asymmetry, motor coordination, and learning function. Angiogenesis and neural plasticity are key neurorestorative elements, and closely associated with poststroke behavioral and histological recovery [5]. Indeed, we observed that TWS119 improves neurological function and simultaneously facilitated angiogenesis and neural plasticity during the chronic phase of experimental stroke. Taken together, our findings indicated that the favorable effects of TWS119 on long-term poststroke outcomes could be attributed, at least partially, to the facilitated angiogenesis and neural plasticity.

TWS119 has a direct modulating effect on peripheral immune cell cells $[18,19]$. In present study, TWS119 modulated microglia/macrophages toward anti-inflammatory phenotype and attenuated inflammation in the peri-infarct cortex. In vitro, we found that the favorable effect of TWS119 on microglial polarization and microgliamediated inflammation status was accompanied with the enhancement of the level of $\beta$-catenin, and partly reversed by selective $W n t / \beta$-catenin pathway blockade targeting Axin in the destruction complex of $\beta$-catenin. Additionally, our prior experiment confirmed TWS119 increased the expression of $\beta$-catenin in the peri-infarct cortex. Thus, we suggested that TWS119 modulated the switch of microglial polarization from pro-inflammatory phenotype to antiinflammatory phenotype following ischemic stroke probably via the $\mathrm{Wnt} / \beta$-catenin pathway. In this mechanism, peroxisome proliferator-activated receptor- $\gamma$ might be the downstream target of $\beta$-catenin, which has been shown in a hemorrhagic stroke model [16]. Furthermore, it is noteworthy that GSK-3 $\beta$, the pharmacological target of TWS119, is a multifunctional kinase and is involved in multiple signaling pathways [36]. In the current study, we cannot exclude the involvement of other mechanisms in the effect of TWS119 on modulating microglial polarization after ischemic stroke. Nevertheless, our study offered a new mechanism on modulating microglial polarization, which enriched the understanding of the role of the Wnt $/ \beta$-catenin signaling pathway in ischemia-induced neuroinflammation. We suggested that activation of the Wnt/ $\mathrm{W}$-catenin pathway during the late phase of ischemic stroke might be a worthwhile strategy on modulating microglial polarization to a protective phenotype. The M1/M2 terminology of microglia is widely debated [37]. Thus, the microglial phenotype was described as pro-inflammatory or antiinflammatory in the current study to avoid the controversy surrounding whether M1 and M2 polarized microglia exist.

Cerebral ischemia induces angiogenesis in the periinfarct cortex of ischemic mice, as does in ischemic stroke patients [38]. In the present study, TWS119 
facilitated post-stroke angiogenesis in the ischemic brain, but failed to directly promote angiogenesis in OGD endothelial cells. Evidence revealed that microglia in anti-inflammatory phenotype promote angiogenesis [39]. Using a conditioned medium transfer system, we found that TWS119 promoted angiogenesis of OGD endothelial cells via anti-inflammatory phenotype microgliamediated amelioration of inflammatory microenvironment, suggesting a proangiogenic effect of TWS119 in anti-inflammatory phenotype polarization-dependent manner. In addition, there existed a spatial and temporal co-localization of angiogenesis, pro-inflammatory to anti-inflammatory switch of microglia phenotype, and amelioration of local inflammatory microenvironment in TWS119-treated mice. Altogether, we suggested that TWS119's efficacy on post-stroke angiogenesis was likely attributed to the local inflammatory microenvironment mediated by microglial polarization proinflammatory/ anti-inflammatory balance state. It is well known that vascular endothelial growth factor (VEGF) is the key pro-angiogenic factor for angiogenesis [40]. The Wnt/ $\beta$ catenin pathway has been confirmed to promote poststroke angiogenesis via modulation on the expression of VEGF in a cerebral ischemia-reperfusion model [41]. Moreover, VEGF has been considered the upstream mechanism of microglial polarization [42]. In the current study, we could not rule out the possibility of VEGF involvement in the advantageous effect of TWS119 on post-stroke angiogenesis. Nevertheless, we indicated that TWS119 directly modulated microglia-mediated inflammatory status toward a better local microenvironment accelerated for neurovascular restoration following ischemic stroke. The neuroinflammation persists into the chronic phase of stroke and participates in all neurorestorative elements, including angiogenesis. Considering the significant correlation of anti-inflammatory cytokine IL-10 and neurological function in our study, we suggested modulation of neuroinflammatory responses shed promising light on neurological recovery following ischemic stroke.

Besides angiogenesis, neural plasticity, including the establishment of new synaptic contacts and sprouting of axonal projections, is another neurorestorative element following stroke. Microglia is involved in synaptic pruning by engulfing synaptic debris [43]. The M2 macrophage is a potent promoter of axonal sprouting by secreting the protective factor IL-10 [44]. In our study, TWS119 promoted neural plasticity accompanied by shift of microglial polarization from pro-inflammatory phenotype to anti-inflammatory phenotype in the periinfarct cortex at 21 days after ischemic stroke, suggesting an exquisite coordination of the two mechanisms. Thus, we speculated TWS119 stimulated neural plasticity might via modulating microglia toward antiinflammatory phenotype. However, contradictory evidence shows that microglia seem irrelevant to axonal regeneration following neuronal injury [45]. To clarify the role of microglia on neural plasticity following stroke, further investigation using primary neuron and primary microglia were needed in our future study.

The present research has several limitations that may impede the universalization of our findings in human ischemic stroke. The focal cerebral ischemic stroke animal model in our study mimic some of the key features of human ischemic stroke, including pathological progression and neurological deficits, but some risk factors of stroke, such as hypertension, diabetes, age, and gender, are not investigated in the present study. Additionally, we did not identify whether the Iba $1^{+}$cells originated from resident microglia or infiltration of blood macrophages. We only demonstrated that TWS119 modulated microglia/macrophages to anti-inflammatory phenotype in vivo. We will further identify the microglia and macrophages from the peri-infarct region of the brain using flow cytometry, in which microglia were stained as $C D 45^{\text {int }} \mathrm{CD} 11 \mathrm{~b}^{+-}$ cells and macrophages stained as $\mathrm{CD} 45^{\text {high }} \mathrm{CD} 11 \mathrm{~b}^{+}$cells. Besides, the role of other immune cells involved in neuroinflammation, especially astrocytes, were not elucidated in our study. Whether Wnt/ $\beta$-catenin pathway activator TWS119 has beneficial effect on astrocytes-mediated neuroinflammation need further investigation.

\section{Conclusion}

Wnt/ק-catenin pathway activator TWS119 ameliorated neuroinflammatory microenvironment following experimental stroke via modulating pro-inflammatory to antiinflammatory phenotype switch of activated microglia and facilitates long-term neurological recovery in an antiinflammatory phenotype polarization-dependent manner. Activation of the $\mathrm{Wnt} / \beta$-catenin pathway during the chronic phase of ischemic stroke might be a promising clinical strategy targeting neuroinflammation via modulating microglia toward anti-inflammatory phenotype and worth further evaluation.

\section{Supplementary information}

Supplementary information accompanies this paper at https://doi.org/10. 1186/s12974-019-1660-8.

\footnotetext{
Additional file 1. Supplementary result. TWS119 with the dose of 10 $\mathrm{mg} / \mathrm{kg}$ was selected in animal experiment. TWS119 activated Wnt/ßcatenin pathway by inhibiting GSK-3 $\beta$. TWS119 improved histological damage in the late stage of stroke. Figure S1 TWS119 at the dose of 10 $\mathrm{mg} / \mathrm{kg}$ was selected in animal experiment. a TWS119 with the dose of 5 $\mathrm{mg} / \mathrm{kg}$ and TWS119 with the dose of $10 \mathrm{mg} / \mathrm{kg}$ upregulated the mRNA expression of $\beta$-catenin $\left(n=8\right.$ per group, ${ }^{*} P<0.05$, $\left.{ }^{* *} P<0.01\right)$. b Neurological functions were evaluated using Adhesive Removal test at day 1, 7 and 14 after stroke. TWS119 with the dose of $10 \mathrm{mg} / \mathrm{kg}$ significantly improved neurological function at day 14 after stroke $(n=8$ per group, TWS119 (10 mg/kg) vs Vehicle, $\left.{ }^{\#} P<0.01\right)$. Figure S2 TWS119 activated Wnt/ $\beta$-catenin pathway by inhibiting GSK-3 $\beta$ and improved histological damage. a Western blot was used to determine the expression of
} 
$\beta$-catenin and GSK-3 314 days after stroke. $b$ and $\mathbf{c}$ TWS1 19-treated mice had a lower level of GSK-3 $\beta$ and a higher level $\beta$-catenin comparing to vehicle mice $\left(n=6\right.$ per group, $\left.{ }^{*} p<0.05,{ }^{* *} p<0.01\right)$. $\mathbf{d}$ Histological damage was assessed by quantification of the infarcted cortex cavitation using CWI. e TWS119 treatment increased the CWI in ischemic mice comparing to vehicle treatment 21 days after stroke $\left(n=8\right.$ per group, ${ }^{*} P<$ 0.05). CWI, Cortical width index. CWI $=100 \% \times$ W.Ipsi / W.contra, W.Ipsi means ipsilateral width, W.contra means contralateral width.

\section{Abbreviations}

Arg: arginase; BrdU: 5-Bromo-2'-deoxyuridine; CWl: Cortical width index; GAP43: Growth-associated protein 43; GSK: Glycogen synthase kinase: Iba1: Ionized calcium-binding adapter molecule 1; IFN-ץ: Interferon- - ; IL: Interleukin; iNOS: Inducible nitric oxide synthase; IWR-1: Reversible inhibitor of Wnt/B-catenin signaling pathway; LPS: Lipopolysaccharide; MCA: Middle cerebral artery; mNSS: Modified neurological severity scores; NO: Nitric oxide; OGD: Oxygen glucose deprivation; PSD95: Postsynaptic dense protein 95; ROI: Region of interest; TGF: Transforming growth factor growth factor; TNF: Tumor necrosis factor; TWS119: 4,6-Disubstituted pyrrolopyrimidine

\section{Acknowledgements}

Not applicable.

\section{Authors' contributions}

DGS, XJZ, and XFL designed the experiments and analyzed and interpreted the data. JMC, XXL, JX, and LZ performed the experiments. DGS wrote the manuscript, and XJZ helped to modify and edited the manuscript. All authors read and approved the final manuscript.

\section{Funding}

This work was supported by the National Natural Science Foundation of China (grant numbers 81571292, 81601152) and the Natural Science Foundation of Hebei Province (grant number H2017206338).

\section{Availability of data and materials}

The datasets generated during and/or analyzed during the current study are available from the corresponding author on reasonable request.

\section{Ethics approval}

All animal experiments in this study have been approved by the Institutional Animal Care and Use Committee of the Second Hospital of Hebei Medical University (permit No. HMUSHC-130318) in accordance with the National Institutes of Health $(\mathrm{NIH})$ Guide for the Care and Use of Laboratory Animals. All protocols were performed to minimize pain or discomfort.

\section{Consent for publication}

Not applicable.

\section{Competing interests}

The authors declare that they have no competing interests.

\section{Author details}

'Department of Neurology, Second Hospital of Hebei Medical University, 215 Hepingxi Road, Shijiazhuang 050000, Hebei, China. ${ }^{2}$ Hebei Key Laboratory of Vascular Homeostasis and Hebei Collaborative Innovation Center for Cardio-cerebrovascular Disease, 215 Hepingxi Road, Shijiazhuang 050000, Hebei, China. ${ }^{3}$ Department of Neurology, First Hospital of Qinhuangdao, Qinhuangdao 066000, Hebei, China.

\section{Received: 24 July 2019 Accepted: 26 November 2019}

\section{Published online: 06 December 2019}

\section{References}

1. Go AS, Mozaffarian D, Roger VL, Benjamin EJ, Berry JD, Borden WB, Bravata DM, Dai S, Ford ES, Fox CS, et al. Executive summary: heart disease and stroke statistics--2013 update: a report from the American Heart Association. Circulation. 2013;127:143-52.

2. Powers WJ, Derdeyn CP, Biller J, Coffey CS, Hoh BL, Jauch EC, Johnston KC, Johnston SC, Khalessi AA, Kidwell CS, et al. American Heart Association/American Stroke Association Focused Update of the 2013 Guidelines for the Early Management of
Patients With Acute Ischemic Stroke Regarding Endovascular Treatment: A Guideline for Healthcare Professionals From the American Heart Association/American Stroke Association. Stroke. 2015;2015(46):3020-35.

3. Shuaib A, Butcher K, Mohammad AA, Saqqur M, Liebeskind DS. Collateral blood vessels in acute ischaemic stroke: a potential therapeutic target. Lancet Neurol. 2011;10:909-21.

4. Stokowska A, Atkins AL, Moran J, Pekny T, Bulmer L, Pascoe MC, Barnum SR, Wetse RA, Nilsson JA, Dragunow M, Pekna M. Complement peptide C3a stimulates neural plasticity after experimental brain ischaemia. Brain. 2017;140:353-69.

5. Cramer SC. Repairing the human brain after stroke. II. Restorative therapies. Ann Neurol. 2008;63:549-60.

6. Wang $X$, Xuan W, Zhu ZY, Li Y, Zhu H, Zhu L, Fu DY, Yang LQ, Li PY, Yu WF. The evolving role of neuro-immune interaction in brain repair after cerebral ischemic stroke. CNS Neurosci Ther. 2018;24:1100-14.

7. Jin Q, Cheng J, Liu Y, Wu J, Wang X, Wei S, Zhou X, Qin Z, Jia J, Zhen X. Improvement of functional recovery by chronic metformin treatment is associated with enhanced alternative activation of microglia/macrophages and increased angiogenesis and neurogenesis following experimental stroke. Brain Behav Immun. 2014:40:131-42.

8. $\quad$ Qin C, Fan WH, Liu Q, Shang K, Murugan M, Wu LJ, Wang W, Tian DS. Fingolimod Protects Against Ischemic White Matter Damage by Modulating Microglia Toward M2 Polarization via STAT3 Pathway. Stroke. 2017;48:3336-46.

9. Hu X, Leak RK, Shi Y, Suenaga J, Gao Y, Zheng P, Chen J. Microglial and macrophage polarization-new prospects for brain repair. Nat Rev Neurol. 2015;11:56-64

10. Ma Y, Wang J, Wang Y, Yang GY. The biphasic function of microglia in ischemic stroke. Prog Neurobiol. 2017;157:247-72.

11. Charriaut-Marlangue C, Leconte C, Csaba Z, Chafa L, Pansiot J, Talatizi M Simon K, Moretti R, Marchand-Leroux C, Baud O, Besson VC. Sex differences in the effects of PARP inhibition on microglial phenotypes following neonatal stroke. Brain Behav Immun. 2018;73:375-89.

12. Ille F, Sommer L. Wnt signaling: multiple functions in neural development Cell Mol Life Sci. 2005;62:1100-8.

13. Libro R, Bramanti P, Mazzon E. The role of the Wnt canonical signaling in neurodegenerative diseases. Life Sci. 2016;158:78-88.

14. Matias D, Dubois LG, Pontes B, Rosario L, Ferrer VP, Balca-Silva J, Fonseca ACC, Macharia LW, Romao L, TCLS ES, et al. GBM-Derived Wnt3a Induces M2-Like Phenotype in Microglial Cells Through Wnt/beta-Catenin Signaling. Mol Neurobiol. 2019;56:1517-30.

15. Ajmone-Cat MA, D'Urso MC, di Blasio G, Brignone MS, De Simone R, Minghetti L. Glycogen synthase kinase 3 is part of the molecular machinery regulating the adaptive response to LPS stimulation in microglial cells. Brain Behav Immun. 2016:55:225-35.

16. Wang Y, Bao DJ, Xu B, Cheng CD, Dong YF, Wei XP, Niu CS. Neuroprotection mediated by the Wnt/Frizzled signaling pathway in early brain injury induced by subarachnoid hemorrhage. Neural Regen Res. 2019;14:1013-24.

17. Wang W, Li M, Wang Y, Li Q, Deng G, Wan J, Yang Q, Chen Q, Wang J. GSK3beta inhibitor TWS119 attenuates rtPA-induced hemorrhagic transformation and activates the Wnt/beta-catenin signaling pathway after acute ischemic stroke in rats. Mol Neurobiol. 2016;53:7028-36.

18. Sabatino M, Hu J, Sommariva M, Gautam S, Fellowes V, Hocker JD Dougherty S, Qin H, Klebanoff CA, Fry TJ, et al. Generation of clinical-grade CD19-specific CAR-modified CD8+ memory stem cells for the treatment of human B-cell malignancies. Blood. 2016;128:519-28.

19. Chen YQ, Zheng L, Aldarouish M, Zhou ZH, Pan N, Liu JQ, Chen FX, Wang LX. Wnt pathway activator TWS119 enhances the proliferation and cytolytic activity of human gammadeltaT cells against colon cancer. Exp Cell Res. 2018;362:63-71.

20. Doyle KP, Fathali N, Siddiqui MR, Buckwalter MS. Distal hypoxic stroke: a new mouse model of stroke with high throughput, low variability and a quantifiable functional deficit. J Neurosci Methods. 2012;207:31-40.

21. Cheng J, Alkayed NJ, Hurn PD. Deleterious effects of dihydrotestosterone on cerebral ischemic injury. J Cereb Blood Flow Metab. 2007:27:1553-62.

22. Hu X, Li P, Guo Y, Wang H, Leak RK, Chen S, Gao Y, Chen J. Microglia/ macrophage polarization dynamics reveal novel mechanism of injury expansion after focal cerebral ischemia. Stroke. 2012;43:3063-70.

23. Liu Y, Tang G, Li Y, Wang Y, Chen X, Gu X, Zhang Z, Wang Y, Yang GY. Metformin attenuates blood-brain barrier disruption in mice following middle cerebral artery occlusion. J Neuroinflammation. 2014:11:177.

24. Caballero-Garrido E, Pena-Philippides JC, Galochkina Z, Erhardt E, Roitbak T. Characterization of long-term gait deficits in mouse dMCAO, using the CatWalk system. Behav Brain Res. 2017;331:282-96. 
25. Freret T, Bouet V, Leconte C, Roussel S, Chazalviel L, Divoux D, Schumann-Bard P, Boulouard M. Behavioral deficits after distal focal cerebral ischemia in mice: Usefulness of adhesive removal test. Behav Neurosci. 2009;123:224-30.

26. Caballero-Garrido E, Pena-Philippides JC, Lordkipanidze T, Bragin D, Yang Y, Erhardt EB, Roitbak T. In Vivo Inhibition of miR-155 Promotes Recovery after Experimental Mouse Stroke. J Neurosci. 2015;35:12446-64.

27. Hayashi-Takagi A, Yagishita S, Nakamura M, Shirai F, Wu YI, Loshbaugh AL, Kuhlman B, Hahn KM, Kasai H. Labelling and optical erasure of synaptic memory traces in the motor cortex. Nature. 2015;525:333-8.

28. Gao C, Qian Y, Huang J, Wang D, Su W, Wang P, Guo L, Quan W, An S, Zhang J, Jiang R. A Three-Day Consecutive Fingolimod Administration Improves Neurological Functions and Modulates Multiple Immune Responses of CCI Mice. Mol Neurobiol. 2017;54:8348-60.

29. Jin Y, Barnett A, Zhang Y, Yu X, Luo Y. Poststroke Sonic Hedgehog Agonist Treatment Improves Functional Recovery by Enhancing Neurogenesis and Angiogenesis. Stroke. 2017:48:1636-45.

30. Zhu L, Kalimuthu S, Gangadaran P, Oh JM, Lee HW, Baek SH, Jeong SY, Lee SW, Lee J, Ahn BC. Exosomes Derived From Natural Killer Cells Exert Therapeutic Effect in Melanoma. Theranostics. 2017;7:2732-45.

31. Plastira I, Bernhart E, Goeritzer M, DeVaney T, Reicher H, Hammer A, Lohberger B, Wintersperger A, Zucol B, Graier WF, et al. Lysophosphatidic acid via LPA-receptor 5/ protein kinase D-dependent pathways induces a motile and pro-inflammatory microglial phenotype. J Neuroinflammation. 2017;14:253.

32. Li Y, Zhang X, Cui L, Chen R, Zhang Y, Zhang C, Zhu X, He T, Shen Z, Dong $L$, et al. Salvianolic acids enhance cerebral angiogenesis and neurological recovery by activating JAK2/STAT3 signaling pathway after ischemic stroke in mice. J Neurochem. 2017;143:87-99.

33. Zhou YX, Shi Z, Singh P, Yin H, Yu YN, Li L, Walsh MP, Gui Y, Zheng XL. Potential Role of Glycogen Synthase Kinase-3beta in Regulation of Myocardin Activity in Human Vascular Smooth Muscle Cells. J Cell Physiol. 2016;231:393-402.

34. Ding S, Wu TY, Brinker A, Peters EC, Hur W, Gray NS, Schultz PG. Synthetic small molecules that control stem cell fate. Proc Natl Acad Sci U S A. 2003;100:7632-7.

35. Wang Y, Liao J, Tang SJ, Shu J, Zhang W. HIV-1 gp120 Upregulates BrainDerived Neurotrophic Factor (BDNF) Expression in BV2 Cells via the Wnt/ beta-Catenin Signaling Pathway. J Mol Neurosci. 2017:62:199-208.

36. Golpich M, Amini E, Hemmati F, Ibrahim NM, Rahmani B, Mohamed Z, Raymond AA, Dargahi L, Ghasemi R, Ahmadiani A. Glycogen synthase kinase-3 beta (GSK-3beta) signaling: Implications for Parkinson's disease. Pharmacol Res. 2015;97:16-26.

37. Ransohoff RM. A polarizing question: do M1 and M2 microglia exist? Nat Neurosci. 2016;19:987-91.

38. Ren C, Yao Y, Han R, Huang Q, Li H, Wang B, Li S, Li M, Mao Y, Mao X, et al. Cerebral ischemia induces angiogenesis in the peri-infarct regions via Notch1 signaling activation. Exp Neurol. 2018;304:30-40.

39. Tian Y, Zhu P, Liu S, Jin Z, Li D, Zhao H, Zhu X, Shu C, Yan D, Dong Z. LL-4polarized BV2 microglia cells promote angiogenesis by secreting exosomes. Adv Clin Exp Med. 2019;28:421-30.

40. Hoffmann CJ, Harms U, Rex A, Szulzewsky F, Wolf SA, Grittner U, LattigTunnemann G, Sendtner M, Kettenmann H, Dirnagl U, et al. Vascular signal transducer and activator of transcription-3 promotes angiogenesis and neuroplasticity long-term after stroke. Circulation. 2015;131:1772-82.

41. Xu Y, Zhang G, Kang Z, Xu Y, Jiang W, Zhang S. Cornin increases angiogenesis and improves functional recovery after stroke via the Ang1/Tie2 axis and the Wnt/beta-catenin pathway. Arch Pharm Res. 2016;39:133-42.

42. Esposito E, Hayakawa K, Ahn BJ, Chan SJ, Xing C, Liang AC, Kim KW, Arai K, Lo EH. Effects of ischemic post-conditioning on neuronal VEGF regulation and microglial polarization in a rat model of focal cerebral ischemia. J Neurochem. 2018;146:160-72.

43. Sellgren CM, Sheridan SD, Gracias J, Xuan D, Fu T, Perlis RH. Patient-specific models of microglia-mediated engulfment of synapses and neural progenitors. Mol Psychiatry. 2017:22:170-7.

44. Kwon MJ, Kim J, Shin H, Jeong SR, Kang YM, Choi JY, Hwang DH, Kim BG Contribution of macrophages to enhanced regenerative capacity of dorsal root ganglia sensory neurons by conditioning injury. J Neurosci. 2013;33:15095-08.

45. Hilla AM, Diekmann H, Fischer D. Microglia Are Irrelevant for Neuronal Degeneration and Axon Regeneration after Acute Injury. J Neurosci. 2017; 37:6113-24

\section{Publisher's Note}

Springer Nature remains neutral with regard to jurisdictional claims in published maps and institutional affiliations.

\section{Ready to submit your research? Choose BMC and benefit from}

- fast, convenient online submission

- thorough peer review by experienced researchers in your field

- rapid publication on acceptance

- support for research data, including large and complex data types

- gold Open Access which fosters wider collaboration and increased citations

- maximum visibility for your research: over $100 \mathrm{M}$ website views per year

At $\mathrm{BMC}$, research is always in progress.

Learn more biomedcentral.com/submissions 